\title{
Plume-exit modeling to determine cloud condensation nuclei activity of aerosols from residential biofuel combustion
}

\author{
Francisco Mena ${ }^{1}$, Tami C. Bond ${ }^{1}$, and Nicole Riemer ${ }^{2}$ \\ ${ }^{1}$ Department of Civil and Environmental Engineering, University of Illinois Urbana-Champaign, Urbana, IL 61801, USA \\ ${ }^{2}$ Department of Atmospheric Sciences, University of Illinois Urbana-Champaign, Urbana, IL 61801, USA \\ Correspondence to: Tami Bond (yark@illinois.edu)
}

Received: 26 January 2017 - Discussion started: 3 February 2017

Revised: 31 May 2017 - Accepted: 2 June 2017 - Published: 7 August 2017

\begin{abstract}
Residential biofuel combustion is an important source of aerosols and gases in the atmosphere. The change in cloud characteristics due to biofuel burning aerosols is uncertain, in part, due to the uncertainty in the added number of cloud condensation nuclei $(\mathrm{CCN})$ from biofuel burning. We provide estimates of the CCN activity of biofuel burning aerosols by explicitly modeling plume dynamics (coagulation, condensation, chemical reactions, and dilution) in a young biofuel burning plume from emission until plume exit, defined here as the condition when the plume reaches ambient temperature and specific humidity through entrainment. We found that aerosol-scale dynamics affect $\mathrm{CCN}$ activity only during the first few seconds of evolution, after which the $\mathrm{CCN}$ efficiency reaches a constant value. Homogenizing factors in a plume are co-emission of semi-volatile organic compounds (SVOCs) or emission at small particle sizes; SVOC co-emission can be the main factor determining plume-exit $\mathrm{CCN}$ for hydrophobic or small particles. Coagulation limits emission of CCN to about $10^{16}$ per kilogram of fuel. Depending on emission factor, particle size, and composition, some of these particles may not activate at low supersaturation $\left(s_{\text {sat }}\right)$. Hygroscopic Aitken-mode particles can contribute to $\mathrm{CCN}$ through self-coagulation but have a small effect on the $\mathrm{CCN}$ activity of accumulation-mode particles, regardless of composition differences. Simple models (monodisperse coagulation and average hygroscopicity) can be used to estimate plume-exit CCN within about $20 \%$ if particles are unimodal and have homogeneous composition, or when particles are emitted in the Aitken mode even if they are not homogeneous. On the other hand, if externally mixed particles are emitted in the accumulation mode without SVOCs, an average hygroscopicity overestimates emitted $\mathrm{CCN}$ by up
\end{abstract}

to a factor of 2. This work has identified conditions under which particle populations become more homogeneous during plume processes. This homogenizing effect requires the components to be truly co-emitted, rather than sequentially emitted.

\section{Introduction}

Residential combustion of biofuels for energy production (including wood, dung, agricultural residues, and charcoal) is an important source of trace gases that play a role in atmospheric chemistry (Chuen-Yu et al., 2011; Williams et al., 2012). Ludwig et al. (2003) estimated that domestic biofuel combustion contributes 7-20\% of the global budget of $\mathrm{CO}_{2}$, $\mathrm{CO}$, and NO. Akagi et al. (2011) estimated that biofuel burning emits $150 \mathrm{Tg} \mathrm{yr}^{-1}$ of non-methane organic compounds.

Biofuel combustion is also an important source of particles, contributing $20 \%$ of primary organic carbon (OC) and black carbon (BC) globally (Bond et al., 2004). These particles affect radiative transfer through interactions with sunlight and clouds. Scattering and absorption of solar radiation by aerosol particles is known as the "direct effect" of aerosols on climate, while the "indirect effect" refers to changes in radiation as aerosol particles alter cloud characteristics. The indirect effect can counteract the warming due to greenhouse gases and absorbing aerosols by increasing the cloud albedo (Twomey, 1974).

Improving model estimates of Earth's radiative response to changes in human activities requires a better understanding of how aerosols with different compositions and mixing states can act as $\mathrm{CCN}$ and, hence, influence cloud properties. 
The overall climate impact of biofuel combustion aerosols is still uncertain because, although biofuel emissions contain BC, an important warming agent (Jacobson, 2000), the magnitude of the indirect effect of biofuel combustion aerosols is still unknown. Jacobson (2010) found that eliminating biofuel soot and gases in addition to fossil fuel soot emissions resulted in a cooling effect and reduced surface air temperatures by $0.4-0.7 \mathrm{~K}$, whereas eliminating fossil fuel soot emissions alone decreased air temperatures by only $0.3-0.5 \mathrm{~K}$. In contrast, Bauer et al. (2010) found that reducing biofuel emissions of black and organic carbon aerosols by $50 \%$ decreased the number concentration of $\mathrm{CCN}$, leading to an increase in radiative forcing of $0.13 \mathrm{~W} \mathrm{~m}^{-2}$, and therefore led to an overall warming effect. Koch et al. (2011) summarized multiple model results, showing that eliminating biofuel burning soot would reduce $\mathrm{CCN}$ concentrations and lead to a warming effect. Kodros et al. (2015) estimated the direct effect of biofuel burning particles to be between -0.02 and $+0.06 \mathrm{~W} \mathrm{~m}^{-2}$, and the indirect effect between -0.02 and $+0.01 \mathrm{~W} \mathrm{~m}^{-2}$. The reason for the discrepancy in these studies lies, in part, in estimating the indirect effect. Bauer et al. (2010), Koch et al. (2011), and Kodros et al. (2015) highlighted the sensitivity of their results to assumptions about aerosol properties such as size distribution and mixing state, that is, how chemical species are distributed across the particle population. Mann et al. (2014) compared models with observations under the AeroCom initiative and reported that some differences might be attributable to missing particle growth or assumptions in size distribution of emissions. Seinfeld et al. (2016) identified the necessity of assessing the level of detail in aerosol microphysical and chemical properties required to represent aerosol-cloud interactions.

In this work, we examine combustion of biofuel to provide energy rather than open biomass burning. The latter refers to large open fires of natural origin or for deforestation and agricultural clearing. Although both activities combust cellulosic fuels, residential biofuel burning plumes dilute to ambient conditions within seconds to minutes. In contrast, biomass burning plumes from an individual event result from uncontrolled combustion of a large area of fuel, and can extend for several kilometers (Trentmann et al., 2006). Open biomass burning contributes $74 \%$ of primary OC and $42 \%$ of BC to the global budget (Bond et al., 2004). Biofuel burning contributes a smaller fraction ( $20 \%$ of primary OC and BC globally) but represents still a large fraction of global emissions that dominates some regions.

In global models of atmospheric chemistry, emissions are instantaneously diluted into the large grid boxes in which the emissions occur. Therefore, plume-scale processes of coagulation, condensation and evaporation, chemical reactions, entrainment of dry air, and dilution are neglected (Poppe et al., 1998; Gao et al., 2003; Jost et al., 2003), although they may affect the properties of aerosols in the plume (Trentmann et al., 2005). In young plumes, defined here as conditions where within-plume concentrations and temperatures are greatly elevated above background, high gas and particle concentrations intensify these processes. Within the first hour, it is common to observe increases in inorganic aerosol mass by factors of 2-10 (Gao et al., 2003; Hobbs et al., 2003), and increases in organic aerosol mass by factors of 1.6-4 (Alvarado and Prinn, 2009; Vakkari et al., 2014). Chemical and physical processes that occur during the early evolution of the plume affect aerosol composition, size, and hygroscopicity and, thereby, the aerosols' ability to become cloud droplets, known as activation. Research on activation properties within young plumes has examined large-scale biomass burning plumes. Previous research has shown that biomass burning particles can be effective $\mathrm{CCN}$. Warner and Twomey (1967), Hobbs and Radke (1969), and Holle (1971) measured increases in $\mathrm{CCN}$ concentrations due to biomass burning emissions. Field studies have measured the particle evolution in biomass burning plumes from minutes to hours or days old (e.g., Liousse et al., 1995; Reid and Hobbs, 1998; Reid et al., 1998, 1999), and modeling efforts have quantified the particle evolution due to coagulation, gas-particle partition, and chemical reactions (e.g., Mason et al., 2001; Trentmann et al., 2002, 2005, 2006; Gao et al., 2003; Jost et al., 2003; Alvarado and Prinn, 2009). To our knowledge, no study has investigated the plume dynamics that affect aerosol evolution within small-scale, young biofuel burning plumes. Furthermore, a distinction of our modeling approach from previous research is that we use a particle-resolved model to quantify the effect of plume-scale processes on the evolution of mixing state, which can contribute to the uncertainty in estimated CCN (Ching et al., 2012).

The objective of this study is to address this research gap for the specific case of residential biofuel combustion. We model the evolution of particles within biofuel burning plumes from emission until plume exit, defined here as the condition when the plume reaches ambient temperature and specific humidity. These simulations are performed for a range of combustion and plume scenarios to estimate likely plume-exit properties and to understand the level of detail required for estimating $\mathrm{CCN}$ concentrations.

\section{Methodology}

A young plume is a rapidly changing environment. After emission, the plume rises due to thermal convection, and entrainment of background air lowers the plume temperature as well as the gas and particle concentration. The decrease in temperature increases relative humidity $(\mathrm{RH})$, but the entrainment of background air counteracts this by decreasing the water content (Trentmann et al., 2006; Shrivastava et al., 2006). The following sections explain how we modeled each of these processes. 


\subsection{Modeling aerosol evolution and $\mathrm{CCN}$ activation: PartMC-MOSAIC}

We modeled the aerosol dynamics within the plume with the Particle Monte Carlo (PartMC) model (Riemer et al., 2009) coupled to the Model for Simulating Aerosol Interactions and Chemistry (MOSAIC) (Zaveri et al., 2008). PartMCMOSAIC is a box model that tracks the composition of individual particles within a Lagrangian air parcel as they evolve due to Brownian coagulation, condensation and evaporation (i.e., gas-particle partitioning), chemical reactions, and dilution. Whereas coagulation and dilution are modeled as stochastic processes with a Poisson distribution, MOSAIC simulates the gas and particle-phase thermodynamics, and gas-particle mass transfer (Riemer et al., 2009; Zaveri et al., 2008). MOSAIC uses the SORGAM scheme to model the formation of low-volatility and semi-volatile products from the oxidation of precursors, and their gas-particle partitioning (Schell et al., 2001; Zaveri et al., 2010). PartMCMOSAIC simulates the mixing ratio of 77 gases and the mass concentration of 20 aerosol species in the plume. For each simulation we used a time step of $0.005 \mathrm{~s}$ and $10^{5}$ computational particles, each one representing a number of simulated particles in the plume.

The high concentrations of gases and particles in a biofuel burning plume, as well as rapid temperature changes, lead to rapid condensation of semi-volatile species and aerosol coagulation. Since PartMC-MOSAIC is a particle-based method, which fully resolves the composition of a representative sample of individual particles in the plume, it is suited to study the evolution of complex biofuel burning aerosol distributions, and to investigate changes that may not be captured by moment-based (Whitby et al., 1997; McGraw et al., 1997) or sectional (Jacobson, 1997) schemes. While the latter two schemes have a long tradition in aerosol modeling studies, they approximate particle size and composition, and hence their predictions are limited by the accuracy of the approximation. For scenarios where mixing state does not have an effect on particle properties, these approaches are sufficient; for instance, if mixing by coagulation can be neglected relative to the condensation rate and no fresh emissions are entering the aerosol population, then all particles evolve equally and a sectional or moment-based scheme will capture the particle evolution. However, in the rapid dilution of young biofuel burning plumes, high coagulation and condensation rates affect particles' composition and size. Capturing the evolution of the mixing state may be important for predicting $\mathrm{CCN}$ activity. To obtain confidence in modeled outcomes in a rapidly changing environment, it is necessary to use a scheme, such as a particle-resolved model, that avoids a priori approximations for the particle mixing state and size - hence, PartMCMOSAIC is a uniquely suited tool for our study.

PartMC-MOSAIC has been used to model aerosol dynamics in urban areas (Riemer et al., 2009, 2010; Zaveri et al., 2010), CCN activation (Ching et al., 2012; Fierce et al.,
2013), and ship plumes (Tian et al., 2014). Within PartMCMOSAIC, we also implemented a module that reproduces the entrainment of background air (Jones, 2014), which allows for a variable water content in the plume.

PartMC-MOSAIC uses prescribed temporal profiles of plume dilution rate, specific humidity, and temperature. Their derivation is detailed in Sect. 2.2. The initial conditions for the simulations are the particle size distribution, the particle composition at emission, and the gas mixing ratios in the plume at emission. To examine plume behavior and sensitivities, these initial conditions are specified and varied as described in Sect. 2.3. In the following section we explain how PartMC-MOSAIC outputs can be used to describe the evolution of the CCN activity of biofuel burning particles.

\subsubsection{CCN activation}

PartMC-MOSAIC returns the composition of individual particles in the plume for each time step of the simulation, which we use to calculate the hygroscopicity of each particle. We use the $\kappa$-Köhler model here to calculate particle hygroscopicity (Petters and Kreidenweis, 2007). The hygroscopicity parameter $\kappa$ comes from a parameterization of Köhler theory (Petters and Kreidenweis, 2007) and represents the hygroscopicity of a substance, that is, its capacity to uptake water. The value of $\kappa$ for a particle is calculated as the volumeaverage of the $\kappa$ of each aerosol component. With the value of $\kappa$ and the particle size, the critical supersaturation at which each particle activates can be calculated using the $\kappa$-Köhler model

We also use several metrics to quantify CCN activity. First, the CCN efficiency is the fraction of particles that activate at a given supersaturation ( $\left.s_{\mathrm{sat}}\right)$. At a sufficiently large $s_{\mathrm{sat}}$, all the particles activate and the CCN efficiency is one. Secondly, we calculate the critical supersaturation of the particle population, consisting of the supersaturation at which $5 \%$ (ssat 5 ), 50\% (ssat 50 ), and $95 \%$ (ssat 95 ) of the plume particles activate. We also evaluate the emission index of $\mathrm{CCN}$ $\left(\mathrm{EI}_{\mathrm{CCN}}\right)$, which is the total number of $\mathrm{CCN}$ present at plume exit per mass of fuel burnt (units of $\mathrm{kg}^{-1}$ ).

In laboratory or field measurements the particle population is not sampled directly at the flame but after a period of cooling, so we use $325 \mathrm{~K}$ as a reference temperature, although any value close to ambient would suffice. We label parameters at this temperature with a "325" subscript, e.g., the particle number concentration $N_{325}$, or count median diameter $\mathrm{CMD}_{325}$. We also calculate the number of $\mathrm{CCN}$ at plume exit normalized to the number of particles at a plume temperature of $325 \mathrm{~K}$, which we term $\mathrm{CCN}_{\text {exit }} / N_{325}$. This parameter indicates the fraction of emitted particles that result in cloud-active particles, accounting for losses due to coagulation and lack of activity due to small size or hydrophobic nature. Similarly, we calculate the fraction of plume particles that reach plume exit $\left(N_{\text {exit }} / N_{325}\right)$. In the calculation, we normalize initial and final plume concentrations by the 
concentration of carbon monoxide (CO) to account for the plume dilution. Since coagulation is modeled as a stochastic process, repeated simulations are not identical, but $\mathrm{EI}_{\mathrm{CCN}}$ differences are within about $3 \%$.

\subsection{Prescribed plume profiles used in PartMC-MOSAIC}

\subsubsection{Plume entrainment}

Buoyancy-induced convection induces both vertical and horizontal dispersion (Trentmann et al., 2005, 2006). A higher dilution rate cools the plume faster, which lowers the saturation vapor pressure of semi-volatile organic compounds (SVOCs) and favors partitioning to the particle phase, but also lowers the concentration of SVOCs in the plume, which favors partitioning to the gas phase (Shrivastava et al., 2006). Hence, dilution influences the predicted concentration of species (Poppe et al., 1998; Mason et al., 2001; Shrivastava et al., 2006; Donahue et al., 2006).

We use the two-parameter dilution model from von Glasow et al. (2003) to represent plume entrainment. This model describes a rising ellipsoidal plume as it rises. The gas or aerosol species concentration dilutes according to

$$
\frac{\mathrm{d} C_{\mathrm{pl}}}{\mathrm{d} t}=\frac{\alpha+\beta}{t}\left(C_{\mathrm{bg}}-C_{\mathrm{pl}}\right),
$$

where $C_{\mathrm{pl}}$ and $C_{\mathrm{bg}}$ are the species' plume and background mass concentration, respectively, $t$ is the time since emission, and $\alpha$ and $\beta$ are empirical parameters describing the dilution in the horizontal and vertical direction, respectively. The solution to this equation is

$C_{\mathrm{pl}}(t)=C_{\mathrm{bkg}}-\left(C_{\mathrm{bkg}}-C_{\mathrm{pl}}\left(t_{0}\right)\right) \times\left(\frac{t_{0}}{t}\right)^{\alpha+\beta}$,

where $t_{0}$ is a reference time for the emission of the plume. Because we model dilution, rather than plume shape, we set $\alpha=\beta$ since one can choose different dilution rates by varying only one of the parameters.

\subsubsection{Specific humidity profile}

Combustion of biofuel produces water due to (a) oxidation of the hydrogen contained in the fuel, also termed "combustion moisture", which can be calculated from the stoichiometry of the combustion reaction, and (b) the release of the water present in the fuel that is not chemically bound to the organic molecules of the fuel. The latter is also termed "fuel moisture", expressed as a percentage of the fuel mass (Parmar et al., 2008).

Combustion moisture ranges from 0.53 to $0.83 \mathrm{~mol}$ of water per mole of $\mathrm{CO}_{2}$ emitted, depending on the type of biofuel (Parmar et al., 2008); we use 0.72 according to the fuel composition in Nussbaumer et al. (2003). A fuel moisture (wet basis) of $50 \%$ gives a total of $1.54 \mathrm{~kg}$ of water emitted per kilogram of biofuel combusted. This corresponds to a water mixing ratio of $4 \times 10^{4} \mathrm{ppmv}$ after stoichiometric combustion and complete evaporation, similar to the value Mason et al. (2001) used for a fresh biomass burning plume $\left(10^{4} \mathrm{ppmv}\right.$ ). The specific humidity profile (Fig. 1a) is derived by using the dilution model (Eq. 1) with an initial and background specific humidity of 0.15 and $0.01 \mathrm{~kg} \mathrm{~kg}^{-1}$, respectively.

\subsubsection{Temperature profile}

The lower heating value of the fuel $\left(16000 \mathrm{~kJ} \mathrm{~kg}^{-1}\right.$; Boundy et al., 2011) combined with an energy balance gives the initial temperature of the parcel $(1560 \mathrm{~K})$ after stoichiometric combustion. The dilution model (Eq. 1) provides the mass of air entrained from the background at each time step. By combining this mass balance with an energy balance, one can derive the temperature at each condition. Discretizing the plume evolution in $k=1,2, \ldots, N$ time steps of width $\Delta t=0.05 \mathrm{~s}$ gives an equation for the temperature profile:

$T_{k+1}=T_{k} \times\left(\frac{T_{k}}{T_{\mathrm{a}}} \frac{\Delta t(\alpha+\beta)}{t_{k}}+\left(1-\frac{\Delta t(\alpha+\beta)}{t_{k}}\right)\right)^{-1}$,

where $t_{k}$ is the time after emission at the $k$ th time step, $T_{\mathrm{a}}$ is the ambient temperature, and $T_{1}$ is the stoichiometric combustion temperature. As explained in Sect. 2.2.1, we assume $\alpha=\beta$. Within $15 \mathrm{~s}$ the plume reaches ambient temperature and specific humidity (i.e., plume exit), so this time period is used for presentation.

\subsubsection{Background species}

Background aerosols and gases are brought into the plume by entrainment. The background gas composition is the same as in the work of Riemer et al. (2009), and there are no additional sources of particles or gases. Background aerosols are composed of $50 \%$ ammonium sulfate and $50 \%$ primary organic aerosol (POA), are lognormally distributed with a count median diameter (CMD) of $500 \mathrm{~nm}$, geometric standard deviation (GSD) of 1.3 , and number concentration of $2.8 \times 10^{8} \mathrm{~m}^{-3}$. We chose this low concentration, characteristic of a clean atmosphere, to focus on the evolution of the plume rather than the effects of background aerosols, since they can significantly affect the CCN activity of plume particles (Fierce et al., 2013).

\subsection{Study design}

About 300 PartMC-MOSAIC simulations with varying initial conditions were conducted, as summarized in Table 1. These initial conditions do not reproduce conditions exactly at the flame exit, because all reported measurements occur after some dilution and cooling. Instead, we chose initial conditions that produce plume-exit properties consistent with 

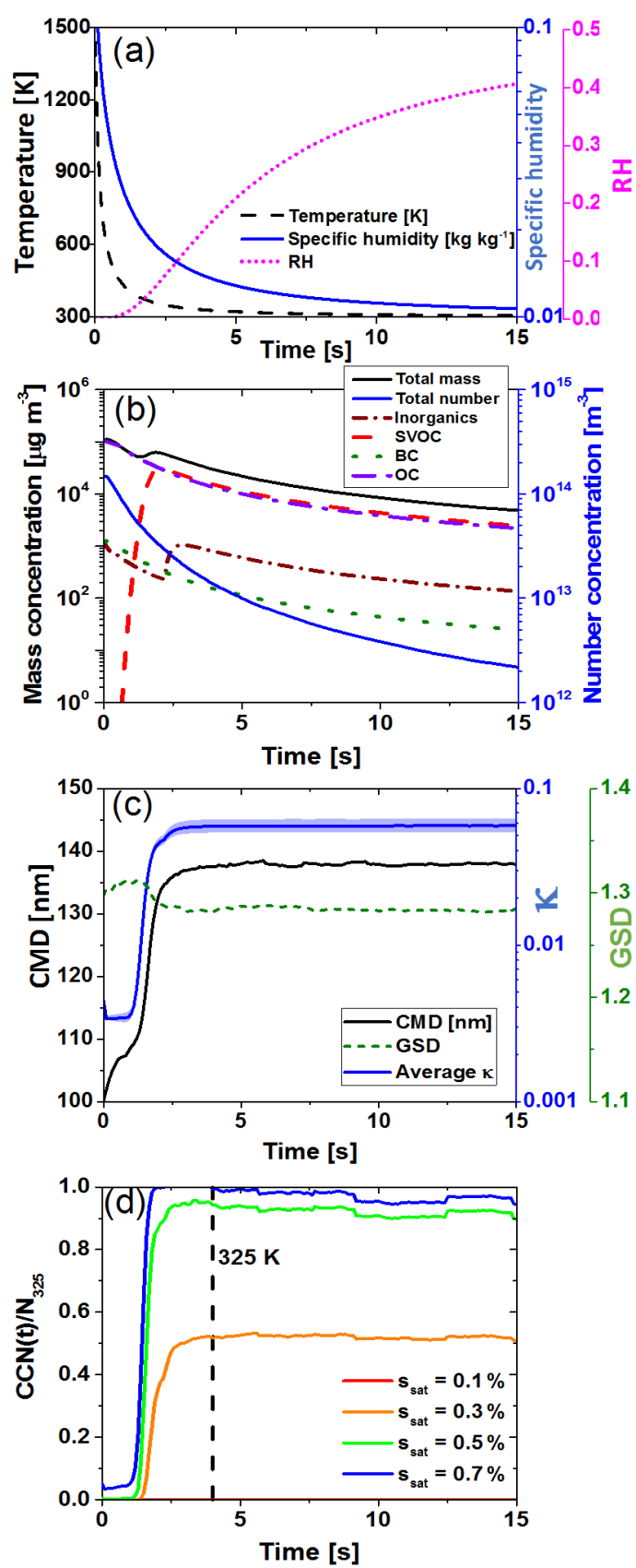

Figure 1. (a) Prescribed profiles of temperature (left axis) and specific humidity (right axis). From these profiles, PartMC-MOSAIC calculates the plume RH (right axis). Time series of (b) mass concentration of plume aerosol species (left axis) and number concentration (right axis), (c) count mean diameter (CMD, left axis), geometric standard deviation (GSD) and the average $\kappa$ of all plume particles (right axis). The shaded area in $\kappa$ is 1 standard deviation from the average. (d) $\mathrm{CCN}(t) / N_{325}$ for $s_{\text {sat }}$ of $0.1,0.3,0.5$, and $0.7 \%$. The vertical black line highlights when the plume temperature is $325 \mathrm{~K}$. Although we modeled the first $30 \mathrm{~s}$, we present results until the plume reaches ambient temperature and $\mathrm{RH}$ (plume exit), i.e., $t=15 \mathrm{~s}$. reported measurements. This allows an evaluation of how plume-exit properties are affected by in-plume dynamics. This section describes how initial conditions or other model parameters were varied to explore the sensitivities of plumeexit CCN. Table 1 also identifies an "illustrative case" which is used to introduce general plume behavior.

\subsubsection{Initial condition: particle composition}

The initial composition of the plume aerosols is taken from laboratory experiments of biomass combustion of chamise, ponderosa pine, and palmetto reported by Lewis et al. (2009). Composition of residential biofuel burning emissions other than BC and POA are scarce, and, although aerosols emitted from biomass burning and residential biofuel combustion are not identical (Hays et al., 2002), their composition is similar (Woo et al., 2003); we use a range of compositions in this work. Since potassium is not represented in PartMC-MOSAIC, all potassium was apportioned as sodium (Na) following the work of Hand et al. (2010) and Zaveri et al. (2008). Detailed composition is given in Table 2. Lewis et al. (2009) reported organic mass, which we use as POA for the initial composition in our simulations (Table 2). BC / OC ratios from in-use cooking with biofuel have been measured between about 0.05 and 0.6 (Roden et al., 2006), consistent with the values used here. Aerosols from the combustion of ponderosa pine have a lower $\mathrm{BC} / \mathrm{OC}$ ratio and inorganic content than those from combustion of chamise, and aerosols from combustion of palmetto have a large inorganic content. The variability in inorganic content gives a wide range of hygroscopicities, as shown in Table 2.

In the initial model input, the aerosol is assigned the composition in Table 2. Some of the constituents may partition to the gas phase at high temperatures (Knudsen et al., 2004), and MOSAIC brings the system to equilibrium within $0.2 \mathrm{~s}$.

\subsubsection{Initial condition: particle size distribution}

Particles at emission are assumed to follow a lognormal size distribution described by a CMD and GSD. Studies on residential stove emissions report measured CMD values between 50 and $300 \mathrm{~nm}$, and GSD values between 1.3 and 2.2 (e.g., Dasch et al., 1982; Hedberg et al., 2002; Tissari et al., 2007). For the initial size distribution we modeled a unimodal distribution with $\mathrm{CMD}_{0}$ of $25,50,100$, or $300 \mathrm{~nm}$, and $\mathrm{GSD}_{0}$ of 1.3. The corresponding initial particle number concentration was calculated using an emission factor of particulate matter (EFPM) of 2, 4, 8, or $12 \mathrm{~g} \mathrm{~kg}^{-1}$. We also modeled scenarios with $\mathrm{GSD}_{0}$ of $1.1,1.3$, or 1.6 , each with a $\mathrm{CMD}_{0}$ of 25,50 , or $100 \mathrm{~nm}$, each with $\mathrm{EF}_{\mathrm{PM}}$ of $4 \mathrm{~g} \mathrm{~kg}^{-1}$.

\subsubsection{Initial condition: gases and semi-volatile organic compounds}

Table 3 presents EFs of the major gas species in the plume. To assemble a plume composition from diverse reports, we 
Table 1. Range of initial conditions and plume parameters analyzed to determine sensitivity. The "Illustrative case" is a simulation used to present the general features observed in the plume evolution.

\begin{tabular}{lll}
\hline Parameter & Scenarios & Illustrative case \\
\hline Initial hygroscopicity & $\kappa_{0}=0.004$ (ponderosa pine), $\kappa_{0}=0.11$ (chamise), & $\kappa_{0}=0.004$ \\
& $\kappa_{0}=0.20$ (palmetto) & $100 \mathrm{~nm}$ \\
Initial CMD and GSD & $\mathrm{CMD}_{0}=25,50,100,300 \mathrm{~nm}$ & 1.3 \\
& $\mathrm{GSD}_{0}=1.1,1.3,1.6$ & $4 \mathrm{~g} \mathrm{~kg}^{-1}$ \\
EFPM & $2,4,8,12 \mathrm{~g} \mathrm{~kg}^{-1}$ & 0.7 \\
Dilution rate & $\alpha=\beta=0.5,0.7,1.0$ & $\mathrm{SVOC1}$ \\
SVOC volatility & $\mathrm{SVOC} 1$ (saturation vapor pressure* $=4.0 \times 10^{-6} \mathrm{~Pa}$ ) or SVOC2 & \\
& (saturation vapor pressure* $=1.2 \times 10^{-4} \mathrm{~Pa}$ ) & $5.62 \mathrm{~g} \mathrm{~kg}-1$ \\
SVOC emission factor $\left(\mathrm{EF}_{\mathrm{SVOC}}\right)$ & 0 (no SVOCs), $5.62 \mathrm{~g} \mathrm{~kg}-1$ & Unimodal \\
Initial aerosol distribution & Unimodal or bimodal distribution & Internal mixture \\
Initial mixing state & External mixture of POA, BC, and ammonium sulfate, or internally mixed &
\end{tabular}

* Saturation vapor pressure at $298 \mathrm{~K}$.

Table 2. Initial composition of aerosols emitted from the combustion of three fuels, from Lewis et al. (2009), and the corresponding volume-average hygroscopicity parameter $\kappa$ (Petters and Kreidenweis, 2007). POA specified here is assumed to be non-volatile.

\begin{tabular}{lrrrr}
\hline Component & $\kappa$ & \multicolumn{3}{c}{ Mass fraction (\%) } \\
\cline { 3 - 5 } & & $\begin{array}{c}\text { Ponderosa } \\
\text { pine }\end{array}$ & Chamise & Palmetto \\
\hline POA & 0.001 & 97.8 & 48.8 & 42.8 \\
$\mathrm{BC}$ & 0 & 1.2 & 27 & 4.4 \\
$\mathrm{SO}_{4}$ & 0.65 & 0.25 & 12.1 & 1.32 \\
$\mathrm{NO}_{3}$ & 0.65 & 0.25 & 1.21 & 0 \\
$\mathrm{Cl}$ & 0.53 & 0.25 & 4.84 & 33 \\
$\mathrm{NH}_{4}$ & 0.65 & 0.12 & 0 & 13.2 \\
$\mathrm{~K}$ & 0.53 & 0.1 & 6.05 & 2.64 \\
Na & 0.53 & 0.03 & 0 & 2.64 \\
Average $\kappa_{0}$ & & 0.004 & 0.11 & 0.20 \\
\hline
\end{tabular}

Table 3. Emission factor of plume gases.

\begin{tabular}{lrl}
\hline Gas & $\begin{array}{r}\text { Emission factor } \\
\left(\mathrm{g} \mathrm{kg}^{-1}\right)\end{array}$ & Reference \\
\hline $\mathrm{CO}_{2}$ & 1626 & Akagi et al. (2011) \\
$\mathrm{NO}_{x}\left(\right.$ as $\left.\mathrm{NO}_{2}\right)$ & 2.04 & Christian et al. (2010) \\
$\mathrm{CO}$ & 42 & Akagi et al. (2011) \\
$\mathrm{NH}_{3}$ & 0.947 & Akagi et al. (2011) \\
$\mathrm{SO}_{2}$ & 0.57 & Burling et al. (2010) \\
$\mathrm{HCl}$ & 0.139 & Burling et al. (2010) \\
$\mathrm{CH}_{4}$ & 2.32 & Akagi et al. (2011) \\
SVOC1, SVOC2 & $0,5.62$ & Akagi et al. (2011) \\
\hline
\end{tabular}

used the ratio between the EF of each species and the EF of $\mathrm{CO}$ and multiplied it by a central estimate of $\mathrm{EF}_{\mathrm{CO}}$ (42 $\mathrm{g} \mathrm{kg}^{-1}$; Akagi et al., 2011).
SVOCs affect the particle size and composition of emitted aerosols (Martin et al., 2013; Vakkari et al., 2014). The exact chemical identification of secondary organic species is not necessary for our purposes; instead, only the volatility is important to describe partitioning in the plume (Donahue et al., 2006) because the short residence time in the plume precludes significant photochemical reactions. The species SVOC1 and SVOC2 in Table 3 are proxies for two SVOCs that we use to explore the effects of gases with different volatilities in the plume. MOSAIC uses the Secondary Organic Aerosol Model (SORGAM) scheme to model the formation and partitioning of low-volatility gas species. SVOC1 and SVOC2 correspond to two of the eight model species specified in SORGAM with vapor pressures of $4.0 \times 10^{-6} \mathrm{~Pa}$ and $1.2 \times 10^{-4} \mathrm{~Pa}$ at $298 \mathrm{~K}$, respectively.

To model different situations of total mass released, we used two values of emission factors $\left(\mathrm{EF}_{\mathrm{SVOC}}\right)$ for all nonmethane hydrocarbons: $\mathrm{EF}_{\mathrm{SVOC}}$ of zero, representing a combustion event with no or negligible emissions of SVOCs, and $5.62 \mathrm{~g} \mathrm{~kg}^{-1}$, a low estimate for cooking stoves (Akagi et al., 2011). Simulations with higher $\mathrm{EF}_{\mathrm{SVOC}}$ values lead to the same conclusions.

\subsubsection{Plume dilution rate}

Dilution rate influences the predicted concentration of species in the plume and, hence, can affect the resulting particle composition and size. We model the range of dilution that could be expected in a biofuel burning plume, represented by the parameter $\alpha$ in Eq. (1). We estimate a value of $\alpha$ between 1 and 2 by comparing modeled and measured temperature profiles of a plume from a wood heating stove, as shown in Supplement Fig. S1. This is equivalent to a dilution rate between 1.0 and $2.7 \mathrm{~s}^{-1}$ when the plume reaches $325 \mathrm{~K}$. Values of $\alpha$ smaller than 0.5 are not likely since this would correspond to dilution rate below $0.02 \mathrm{~s}^{-1}$ at $325 \mathrm{~K}$, or a dilution ratio smaller than $5: 1$, and would take the plume more 
than $30 \mathrm{~s}$ to reach ambient temperature. On the other hand, values of $\alpha$ greater than 1 do not affect the mass of SVOC condensed but reduce the coagulation rate so that changes in particle size and mixing state are less pronounced. Hence, simulations with $\alpha$ greater than 1 do not yield different CCN activity at plume exit, although the plume reaches ambient temperature faster. Therefore, we present scenarios modeled with $\alpha=\beta=0.5,0.7$, and 1.0.

\subsubsection{Mixing state: external vs. internal mixture as initial condition}

Biofuel combustion is a dynamic process, varying between flaming and smoldering. Hence, the composition of the particles emitted is not perfectly homogeneous and might change with time. To assess the effect of the initial mixing state on plume-exit $\mathrm{CCN}$, we used as initial condition an external mixture containing three unimodal populations: an inorganic mode composed of ammonium sulfate, one of non-volatile POA, and one of BC. The three populations have the same $\mathrm{CMD}_{0}$ and $\mathrm{GSD}_{0}$, and the mass of each population follows the composition of Chamise in Table 2 ( $\kappa_{0}$ of 0.11 ). We compare and contrast the results of the external mixture with a case where we assume an internal mixture of the same components as initial condition, with the same mass fractions as the external mixture case.

\subsubsection{Role of Aitken-mode particles in determining plume-exit CCN}

Biofuel burning aerosols often have bimodal size distributions, containing an Aitken mode (particles less than $100 \mathrm{~nm}$ ) and an accumulation mode (particles larger than $100 \mathrm{~nm}$ and less than $1 \mu \mathrm{m}$ ) (e.g., Hedberg et al., 2002; Li et al., 2007). The particles in the Aitken mode have a high coagulation rate, and inorganic species are usually more abundant in this mode (Torvela et al., 2014).

We modeled a plume in which the initial distribution contained an Aitken mode with $\mathrm{CMD}_{1}=30 \mathrm{~nm}$ and an accumulation mode with $\mathrm{CMD}_{2}=100 \mathrm{~nm}$. We studied two different cases: an internal mixture in which particles in both modes have the same composition, and an external mixture in which the Aitken mode is composed of only ammonium sulfate and the accumulation mode is composed of a mixture of $\mathrm{BC}$ and POA. We call these the "homogeneous" and "heterogeneous" bimodal distribution scenarios, respectively. In both cases the mass fractions of $\mathrm{BC}, \mathrm{POA}$, and ammonium sulfate of the overall population are the same. To study the effect of small particles on plume-exit CCN we also varied the initial concentration of the Aitken mode $\left(N_{0, \text { Aitken }}\right)$ and changed the concentration of the accumulation mode to keep the same particulate mass emitted ( $\mathrm{EF}_{\mathrm{PM}}$ of $4 \mathrm{~g} \mathrm{~kg}^{-1}$ ). Since the mass

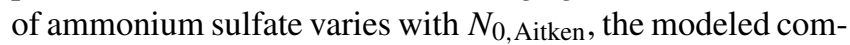
position differs from that described in Table 2 in these cases.
We also repeated simulations with either the Aitken or accumulation mode removed, leaving only the remaining mode as a unimodal distribution. By comparing the resulting activation properties of these simulations, we assessed the role of the Aitken-mode aerosols on the resulting $\mathrm{CCN}$ concentration.

\subsection{Simple estimates of condensation and coagulation}

While PartMC-MOSAIC models the aerosol population in great detail, this detail may not be necessary to capture all aerosol evolution. We assess the plume processes that can be simplified or parameterized by comparing simple estimates of the evolution of particle properties with PartMC-MOSAIC predictions. These simple estimates are described below.

For coagulation, we estimated the number of particles lost at each time step using the formulation for a monodisperse aerosol distribution (Seinfeld and Pandis, 2006),

$\frac{\mathrm{d} N}{\mathrm{~d} t}=4 \sqrt{\frac{6 k_{\mathrm{B}} T D}{\rho}} N^{2}$,

where $N$ is the particle number concentration, $k_{\mathrm{B}}$ is Boltzmann's constant, $T$ is the plume's temperature, and $D$ and $\rho$ are the particle diameter and density, respectively.

Regarding condensation, from the total mass condensed determined by PartMC-MOSAIC, we derived the consequent increase in particle size (CMD) by assuming that the GSD stays constant. We also calculated an average hygroscopicity $\kappa$ for all the plume particles to assess whether it could reproduce the results obtained with PartMC-MOSAIC. With the derived CMD, average $\kappa$, and particle number concentration, we estimated the plume-exit $\mathrm{CCN}$ and compared with PartMC-MOSAIC predictions. This discussion is presented in Sect. 3.1.

\section{Results}

We begin the discussion of results with an illustrative case (Sect. 3.1) that demonstrates the evolution within the plume for a reference case, and then evaluate how this evolution changes with variations in the initial conditions (Sects. 3.2 through 3.5). Inputs for the illustrative case are listed in Table 1 .

\subsection{Illustrative case}

Figure $1 \mathrm{~b}$ shows the evolution of the mass concentration of the main aerosol species for the illustrative case. SVOCs condense within the first two seconds of the plume's evolution, driven by the rapid drop in temperature (Fig. 1a). The increase in inorganic species shortly after SVOC condensation consists mostly of $\mathrm{NH}_{4} \mathrm{Cl}$ that condenses at temperatures below $340 \mathrm{~K}$ (Zaveri et al., 2008). Condensation of $\mathrm{NO}_{3}$ constitutes only $10 \%$ of the inorganic mass. Number concentration 
is also shown in Fig. 1b; it decreases faster than mass concentration due to coagulation.

The effect of the rapid condensation of SVOCs and inorganic species on particle size and hygroscopicity can be seen in Fig. 1c. CMD increases from 100 to $140 \mathrm{~nm}$ (black line), and the average $\kappa$ of the plume aerosols increases from 0.004 to 0.06 (blue line). By repeating the simulations with either condensation or coagulation disabled and comparing the results, we conclude that about $20 \%$ of the increase in CMD can be attributed to coagulation, and the remaining $80 \%$ is from condensation of SVOCs. In this scenario, where the particles begin with a homogeneous composition, $\kappa$ of individual particles changes only by condensation. Once the plume cools below $350 \mathrm{~K}(t=2.4 \mathrm{~s})$, the CMD and average $\kappa$ change by less than 1 and $3 \%$, respectively. Since most particle sampling occurs at conditions below 300-325 K, aerosol properties measured at this temperature are sufficient to represent particles later in the evolution of a young plume.

Since condensation is the main cause of increased particle size and hygroscopicity, it is also the main factor driving particle activation. Coagulation increases $\mathrm{CCN}$ efficiency by about $20 \%$ by increasing particle size, but it also lowers plume-exit CCN by $25 \%$ due to the decrease in particle number. The increase in particle size and hygroscopicity leads to an increase in the fraction of particles that can become $\mathrm{CCN}$, as shown in Fig. 1d for different $s_{\text {sat }}$ values. About half of the plume particles can activate at $s_{\text {sat }}$ of $0.3 \%$, while most, but not all, particles activate at $s_{\text {sat }}$ of $0.5 \%$. Regardless of the value of $s_{\mathrm{sat}}$ chosen, $\mathrm{CCN}(t) / N_{325}$ changes by less than $3 \%$ after the initial rapid evolution of the plume.

Transformation in this illustrative case can be summarized as a rapid increase in particle size and hygroscopicity dominated by SVOC condensation, and a decrease in particle number concentration determined by the coagulation rate and plume dilution. Since condensation is the main factor, one can estimate activation with a simple analysis as described in Sect. 2.4. Using only the condensed SVOC mass to derive the increase in particle size, and both the condensed SVOC and inorganic mass to derive the increase in hygroscopicity, one can estimate a CCN efficiency within $15 \%$ of PartMCMOSAIC's result, the mismatch being due to neglecting the growth by coagulation. Furthermore, using the monodisperse coagulation model to estimate the particle loss, one can estimate $\mathrm{CCN}_{\text {exit }} / N_{325}$ within $19 \%$. Despite the complexity of the processes occurring in a fresh plume, at least in this illustrative case they can be qualitatively described with simple models.

\subsection{Initial size and hygroscopicity, without co-emitted SVOCs}

In this section we analyze the sensitivity of plume-exit $\mathrm{CCN}$ to initial particle size and composition, when SVOCs are not emitted simultaneously. Figure 2a to c show the 12 scenar-
Table 4. $\mathrm{EI}_{\mathrm{CCN}}\left(\mathrm{kg}^{-1}\right)$ at $s_{\mathrm{sat}}$ of $0.7 \%$ for scenarios with $\mathrm{CMD}_{0}=25,50,100$, and $300 \mathrm{~nm}$ (i.e., $\mathrm{CMD}_{325}=60,78,111$, and $304 \mathrm{~nm})$, and $\kappa_{0}=0.004,0.11$, and $0.2\left(\kappa_{325}=0.02,0.13\right.$, and 0.25 ), and no co-emitted SVOCs.

\begin{tabular}{lccc}
\hline \multicolumn{3}{l}{$\mathrm{EI}_{\mathrm{CCN}}$ at a $s_{\mathrm{sat}}$ of $0.7 \%\left(\times 10^{15}\right)$} \\
\hline & \multicolumn{3}{c}{$\kappa_{0}$} \\
\cline { 2 - 4 } $\mathrm{CMD}_{0}$ & 0.004 & 0.11 & 0.2 \\
$(\mathrm{~nm})$ & & & \\
\hline 25 & 1.05 & 5.73 & 7.44 \\
50 & 1.86 & 6.54 & 7.84 \\
100 & 2.57 & 3.46 & 3.14 \\
300 & 0.21 & 0.17 & 0.15 \\
\hline
\end{tabular}

ios analyzed: combinations of $\mathrm{CMD}_{0}$ of $25,50,100$, and $300 \mathrm{~nm}$, with $\kappa_{0}$ of $0.004,0.11$, and 0.2 .

Particles in all scenarios follow an evolution similar to that of the illustrative case: a rapid increase in hygroscopicity due to condensation of inorganic species (from $\kappa_{0}=0.004,0.11$, and 0.2 , to $\kappa_{325}=0.02,0.13$, and 0.25 , respectively, with $\kappa_{325}$ the same within 0.01 for the different $\mathrm{CMD}_{0}$ ), and in size due to the high coagulation rate, especially for small particles (from $\mathrm{CMD}_{0}=25,50,100$, and $300 \mathrm{~nm}$ to $\mathrm{CMD}_{325}=60$, 78, 111 and $304 \mathrm{~nm}$, respectively, with $\mathrm{CMD}_{325}$ the same within $5 \mathrm{~nm}$ for the different $\kappa_{0}$ ). In particular, it is not possible to obtain a $\mathrm{CMD}_{325}$ of $50 \mathrm{~nm}$ or smaller with an $\mathrm{EF}_{\mathrm{PM}}$ above $3 \mathrm{~g} \mathrm{~kg}^{-1}$ due to the high coagulation rate. Below $325 \mathrm{~K}$ there is no more condensation, and coagulation is the only process affecting particle size. During the short time between this temperature and plume exit, size changes by less than $5 \%$.

Figure 2a shows the critical supersaturations of the particle populations at plume exit for these scenarios. The midpoint is the supersaturation at which $50 \%$ of the plume particles become CCN (ssat 50 ), and the error bars indicate the supersaturation at which $5 \%$ (ssat 5 ) and $95 \%$ (ssat ${ }_{95}$ ) of the particles become CCN. Despite the high critical supersaturations of small particles, e.g., $\mathrm{CMD}_{325}$ below $100 \mathrm{~nm}$ in Fig. 2a, they can contribute substantially to $\mathrm{EI}_{\mathrm{CCN}}$ for supersaturations above $0.3 \%$, as shown in Fig. $2 \mathrm{~b}$ and Table 4. This is because more small particles are emitted for a given $\mathrm{EF}_{\mathrm{PM}}$, which eventually can become CCN. However, small particles with low inorganic content form $\mathrm{CCN}$ with low efficiency, with $\mathrm{CCN}_{\text {exit }} / N_{325}$ differing by up to a factor of 7 in the scenarios with $\kappa_{325}$ of 0.02 and 0.25 (black columns in Fig. 2c).

We also conducted simulations using size distributions with $\mathrm{GSD}_{0}$ of 1.1, 1.3, and 1.6, each with $\mathrm{CMD}_{0}$ of 25, 50, or $100 \mathrm{~nm}$. As with the CMD and $\kappa$, the GSD changes less than $5 \%$ below $325 \mathrm{~K}$. Regarding CCN activity, the scenario with $\mathrm{GSD}_{0}$ of 1.1 can have $\mathrm{EI}_{\mathrm{CCN}}$ up to twice as large as with $\mathrm{GSD}_{0}$ of 1.6. This is because a wider size distribution 

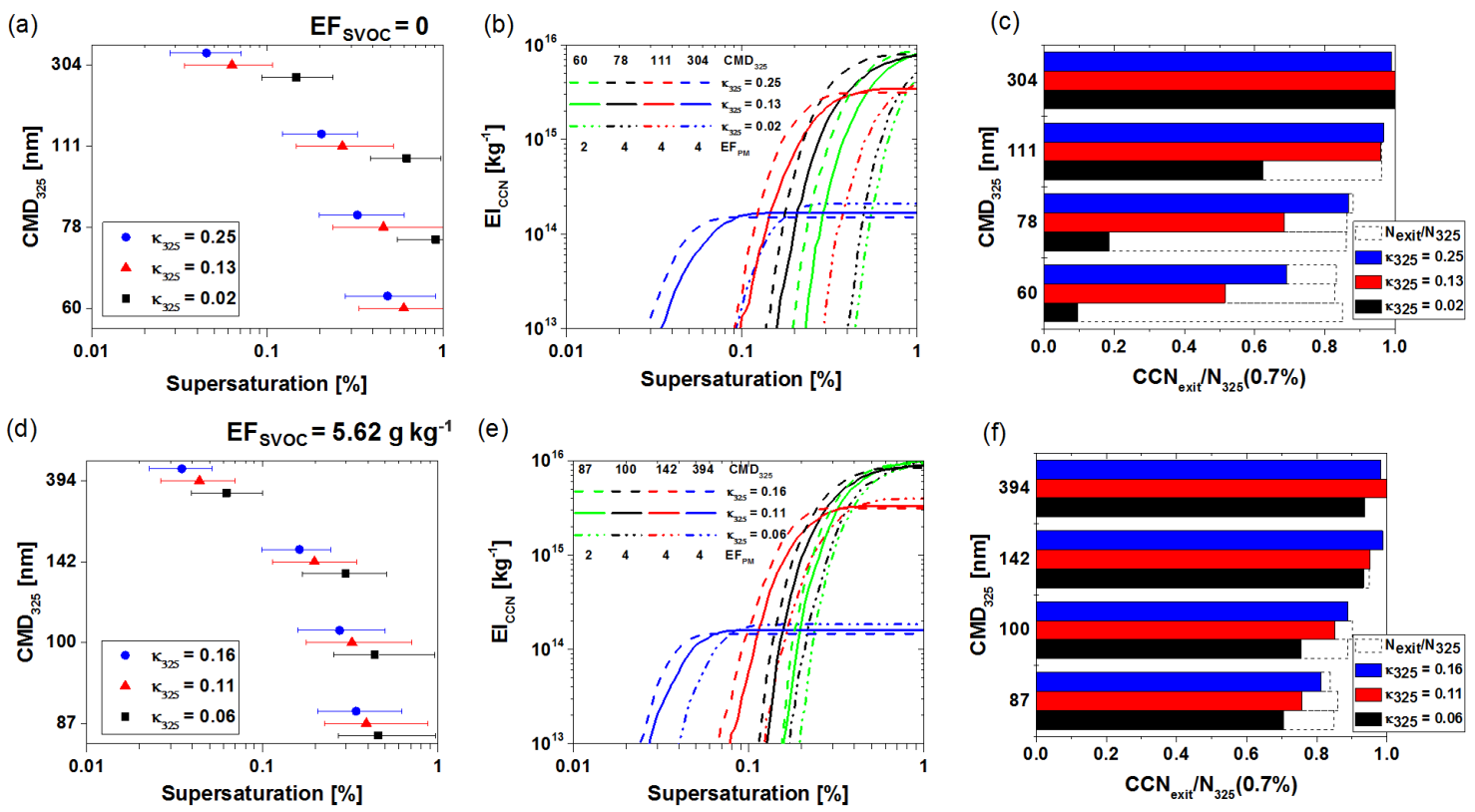

Figure 2. (a) Critical supersaturation of particle populations (ssat 5 , ssat 50 , and ssat 95 ), (b) $\mathrm{EI}_{\mathrm{CCN}}$, and (c) $\mathrm{CCN}_{\text {exit }} / N_{325}$ at $s_{\mathrm{sat}}$ of $0.7 \%$ for four different initial sizes $\left(\mathrm{CMD}_{0}=25,50,100\right.$, and $\left.300 \mathrm{~nm}\right)$ and compositions $\left(\kappa_{0}=0.004,0.11\right.$, and 0.20$)$. Labels show CMD and $\kappa$ at $325 \mathrm{~K}$. No SVOCs are co-emitted $\left(\mathrm{EF}_{\mathrm{SVOC}}=0\right)$. Panels $(\mathbf{d})$, (e), and (f) show the same scenarios but for $\mathrm{EF}_{\mathrm{SVOC}}=5.62 \mathrm{~g} \mathrm{~kg}-1 . \mathrm{The}^{-}$ scenario with $\mathrm{CMD}_{0}=25 \mathrm{~nm}$ uses $\mathrm{EF}_{\mathrm{PM}}$ of 2 instead of $4 \mathrm{~g} \mathrm{~kg}^{-1}$ to achieve smaller $\mathrm{CMD}_{325}$ at plume exit.

allocates some of the mass to particles too small to become $\mathrm{CCN}$.

\subsection{Effects of co-emitted SVOCs}

The scenarios described in the previous sections were also modeled with co-emitted SVOCs $\left(\mathrm{EF}_{\mathrm{SVOC}}\right.$ of $\left.5.62 \mathrm{~g} \mathrm{~kg}^{-1}\right)$. Results appear in Fig. 2d, e, and f. The main effect of coemitted SVOCs is the particle size increase due to the added mass, and the consequent decrease in critical supersaturation as shown in Fig. 2d and Table 5. The change in hygroscopicity is more varied; simulations with $\mathrm{EF}_{\mathrm{SVOC}}$ of $5.62 \mathrm{~g} \mathrm{~kg}^{-1}$ and an initial hygroscopicity $\kappa_{0}$ of $0.004,0.11$, and 0.20 changed to $\kappa_{325}$ of $0.06,0.11$, and 0.16 , respectively. Engelhart et al. (2012) observed a similar change in aged biomass burning plumes; condensation of organic species increases the hygroscopicity of hydrophobic particles but decreases it for more hygroscopic particles. This is because SVOC condensation decreases the volume fraction of the (more hygroscopic) inorganic species. Hence, the inorganic content plays less of a role in determining the $\mathrm{CCN}$ activity of small particles when SVOCs are co-emitted, as can be seen by comparing Fig. 2c and f. Results of simulations with SVOC1 and SVOC2 are the same within a few percent.

For $\mathrm{EF}_{\mathrm{SVOC}}$ above about $3 \mathrm{~g} \mathrm{~kg}^{-1}$, condensation dominates the in-plume increase in particle size, change in hygroscopicity, and, hence, critical supersaturation. This is shown in Table 5 for ssat 50 and different values of $\mathrm{EF}_{\mathrm{SVOC}}$ and $\mathrm{EF}_{\mathrm{PM}}$. Changes in $\mathrm{EF}_{\mathrm{PM}}$ and, hence, particle number emit-
Table 5. Median critical supersaturation ( $\mathrm{ssat}_{50}$ ) from simulations with $\mathrm{EF}_{\mathrm{PM}}$ of 2, 4, or $8 \mathrm{~g} \mathrm{~kg}^{-1}$, and $\mathrm{EF}_{\mathrm{SVOC}}$ of $0,3,5.62$, and $10 \mathrm{~g} \mathrm{~kg}^{-1}$. An initial size of $\mathrm{CMD}_{0}$ of $25 \mathrm{~nm}$ was used to model a high coagulation rate.

\begin{tabular}{lrrrr}
\hline \multicolumn{5}{c}{ ssat $_{50}(\%)$} \\
\hline \multicolumn{4}{c}{ EF $_{\text {SVOC }}\left(\mathrm{g} \mathrm{kg}^{-1}\right)$} \\
\cline { 2 - 5 } $\mathrm{EF}_{\mathrm{PM}}$ & 0 & 3 & 5.62 & 10 \\
$\left(\mathrm{~g} \mathrm{~kg}^{-1}\right)$ & & & & \\
\hline 2 & $>1$ & 0.65 & 0.48 & 0.36 \\
4 & $>1$ & 0.64 & 0.48 & 0.38 \\
8 & 0.91 & 0.63 & 0.49 & 0.38 \\
\hline
\end{tabular}

ted and their coagulation rate, have a small effect in ssat ${ }_{50}$. For $\mathrm{EF}_{\mathrm{SVOC}}$ smaller than about $3 \mathrm{~g} \mathrm{~kg}^{-1}$, particles grow more by coagulation.

These results indicate that co-emission of SVOC material can be the main factor determining the $\mathrm{CCN}$ activity of biofuel burning aerosols. The $\mathrm{CCN}$-modifying effect may be achieved only when SVOCs and primary aerosols are emitted simultaneously; it is not enough for them to be emitted from the same fire at different times.

\subsection{Initial mixing state}

In the previous scenarios, all particles had the same composition at emission. In this section we study the importance of 

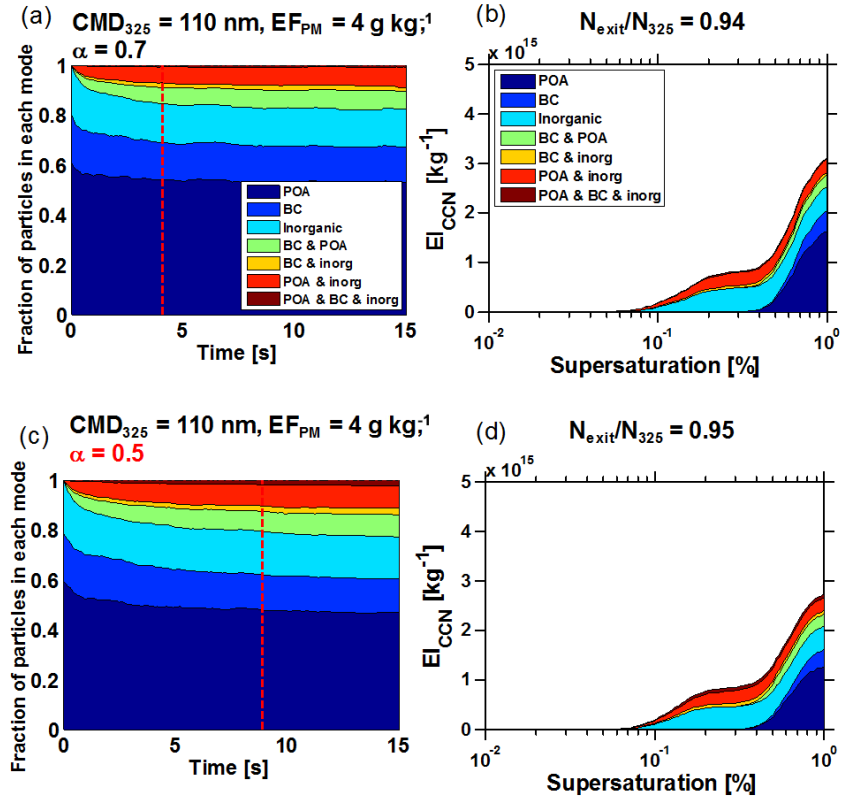

(e) $\mathrm{CMD}_{325}=110 \mathrm{~nm}, \mathrm{EF}_{\mathrm{PM}}=12 \mathrm{~g} \mathrm{~kg}^{-1}$,
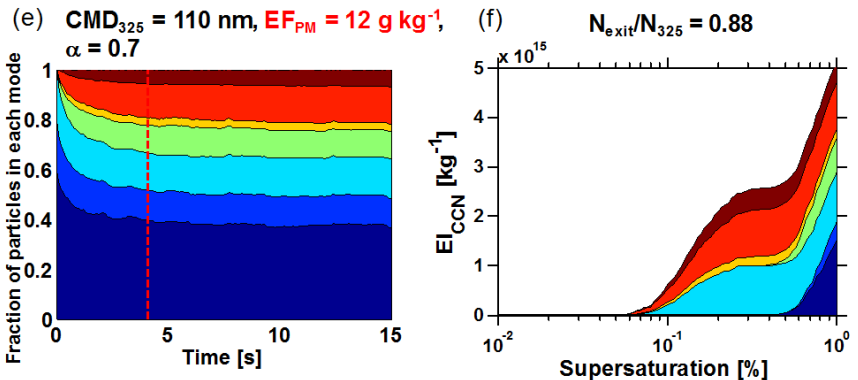

(g) $\mathrm{CMD}_{325}=70 \mathrm{~nm}, \mathrm{EF}_{\mathrm{PM}}=\mathbf{4} \mathbf{~ g ~ k g - 1}$,
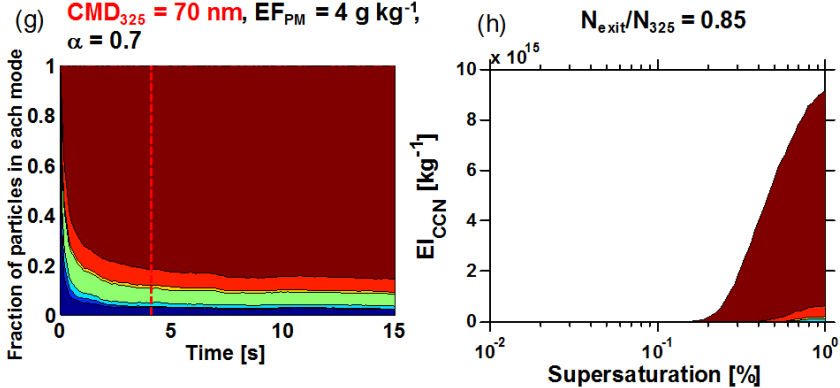

Figure 3. Fraction of particles in each mode (POA, BC, inorganic, or coagulated) as the plume evolves, showing how different initial conditions affect the coagulation between modes in an external mixture. (a) Scenario with $\mathrm{CMD}_{0}$ of $100 \mathrm{~nm}$ and $\mathrm{GSD}_{0}$ of 1.3 , EFPM of $4 \mathrm{~g} \mathrm{~kg}^{-1}, \alpha$ of 0.7 , and no SVOCs. The other panels are the same scenario modified with (c) slower dilution $(\alpha=0.5)$, (e) EFPM of $12 \mathrm{~g} \mathrm{~kg}^{-1}$, or $(\mathrm{g}) \mathrm{CMD}_{0}=25 \mathrm{~nm}\left(\mathrm{CMD}_{325}=70 \mathrm{~nm}\right)$. The vertical red line highlights when the plume temperature is $325 \mathrm{~K}$. Panels $(\mathbf{b})$, $(\mathbf{d})$, (f), and (h) are the corresponding $\mathrm{EI}_{\mathrm{CCN}}$ graphs to scenarios (a), (c), (e), and (g), respectively.

the initial mixing state for plume-exit CCN. As initial condition we use an external mixture of three modes, POA, BC, and ammonium sulfate, all with the same size distribution, and we analyze how results differ from the case in which the initial aerosols are internally mixed, corresponding to $\kappa_{0}$ of 0.11 in Table 2. Unless otherwise stated, no SVOCs are coemitted.

The particle size distribution follows the same evolution as in the previous scenarios. The hygroscopicity, however, is much more varied. Since PartMC-MOSAIC keeps track of the mode where each particle started, as well as each coagulation event, we can derive the fraction of particles that have coagulated with a particle from another mode. This is presented in Fig. 3, which shows pairs of graphs for four scenarios, with the left panel of each pair demonstrating the evolution of coagulated particles with time, and the right panel showing the plume-exit distribution of $\mathrm{CCN}$ as a function of supersaturation and particle type. Fig. $3 \mathrm{~b}$ shows that coagulated and inorganic particles contribute the most to plumeexit CCN. Particles in the POA and BC mode that do not coagulate remain too hydrophobic or too small, and contribute to $\mathrm{CCN}$ only at supersaturations close to $1 \%$.

The fraction of particles that coagulate with another mode is sensitive to initial size: about $1 \%$ for $\mathrm{CMD}_{0}$ of $300 \mathrm{~nm}$ $\left(\mathrm{CMD}_{325}\right.$ of $\left.303 \mathrm{~nm}\right), 17 \%$ for $\mathrm{CMD}_{0}$ of $100 \mathrm{~nm}\left(\mathrm{CMD}_{325}\right.$ of $110 \mathrm{~nm}$, Fig. $3 \mathrm{a}$ and b), and $97 \%$ for $\mathrm{CMD}_{0}$ of $25 \mathrm{~nm}$ $\left(\mathrm{CMD}_{325}\right.$ of $70 \mathrm{~nm}$, Fig. $3 \mathrm{~g}$ and h). Slower dilution rates (Fig. 3c) and higher $\mathrm{EF}_{\mathrm{PM}}$ (Fig. 3e) also increase the coag- ulation between modes, but these factors affect plume-exit CCN substantially less than initial particle size, as can be seen by comparing Fig. $3 \mathrm{~d}$ and $\mathrm{f}$ with Fig. $3 \mathrm{~h}$. A higher dilution rate $(\alpha=1)$ actually decreases the coagulation rate; hence, it affects plume-exit CCN by just a few percent. While other research has indicated that dilution is an important factor in plume chemistry and aerosol composition (Poppe et al., 1998; Shrivastava et al., 2006; Donahue et al., 2006), that work addresses large plumes aging over hours, while our work focuses on small plumes and aging timescales of seconds.

As shown in Fig. 3a, most of the coagulation between modes occurs early in the evolution of the plume. This fraction of coagulated particles increases by less than $16 \%$ below $325 \mathrm{~K}$. This implies that activation properties are set early in the plume evolution, with ssat 50 changing by only $10 \%$ between $325 \mathrm{~K}$ and plume exit.

Figure 4 shows how $\mathrm{EI}_{\mathrm{CCN}}$ differs when particles of different size are externally mixed at emission, as compared with the internal mixture case (solid and dashed lines, respectively). For $\mathrm{CMD}_{0}$ of $50 \mathrm{~nm}$ (black lines), $\mathrm{EI}_{\mathrm{CCN}}$ of both mixing states is within $20 \%$. For $\mathrm{CMD}_{0}$ of $300 \mathrm{~nm}$ (blue lines) $\mathrm{EI}_{\mathrm{CCN}}$ is the same within $5 \%$ for $s_{\text {sat }}$ above $0.2 \%$. The deviation grows with decreasing supersaturation, up to a factor of 2.5 at $s_{\text {sat }}$ of $0.1 \%$. This low sensitivity to initial mixing state occurs because small particles have a higher coagulation rate and hence have a more homogeneous composition at plume exit. This is consistent with Che et al. (2016), 


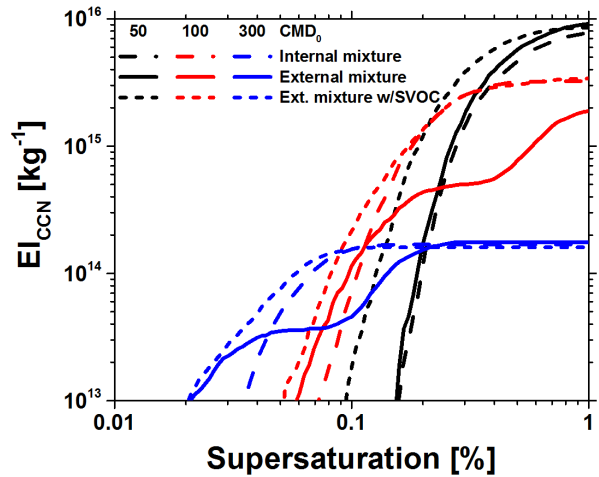

Figure 4. $\mathrm{EI}_{\mathrm{CCN}}$ for different initial mixing states and initial $\mathrm{CMD}_{0}$ of $50 \mathrm{~nm}$ (black), $100 \mathrm{~nm}$ (red), or $300 \mathrm{~nm}$ (blue). In the internal mixture case (dashed lines) all particles have the same initial composition, and no co-emitted SVOCs. The external mixture scenarios (solid lines) have an initial composition of three modes (POA, $\mathrm{BC}$, and inorganic) with the same mass fraction as in the internal mixture, and no co-emitted SVOCs. The dotted line is the same external mixture scenario but now with co-emitted SVOCs $\left(\mathrm{EF}_{\mathrm{SVOC}}=5.62 \mathrm{~g} \mathrm{~kg}^{-1}\right)$.

who observed that particles growing in the Aitken mode become more internally mixed in part due to coagulation. On the other hand, large particles have a low critical supersaturation, regardless of mixing state. For intermediate particles with $\mathrm{CMD}_{0}$ of $100 \mathrm{~nm}$ (red lines) $\mathrm{EI}_{\mathrm{CCN}}$ differs by up to a factor of 4, indicating that particles are still externally mixed by plume exit. However, when SVOCs are co-emitted (red dotted line), the two scenarios differ by only 5 to $20 \%$ (red dashed line), because the added SVOC mass also has a homogenizing effect on the composition of the particle population. Hence, the initial mixing state has a smaller effect on plume-exit CCN when SVOCs are co-emitted.

Figure 5 shows the distribution of critical supersaturation at plume exit, similar to the presentation in Fig. 2. The distribution calculated using the composition from PartMCMOSAIC is compared with the one using an average hygroscopicity for all particles. The use of an average hygroscopicity for particles that started with an external mixture leads to overestimating the $\kappa$ of POA and BC particles and, hence, their contribution to CCN. This is consistent with the field studies of Wang et al. (2010) and Che et al. (2016), who found that the internal mixture assumption overestimates CCN number by 10 to $45 \%$. Figure 5 shows that an average hygroscopicity underestimates ssat 50 by at least $60 \%$ in the scenarios with $\mathrm{CMD}_{325}$ of $110 \mathrm{~nm}, \alpha$ of 0.5 , or $\mathrm{EF}_{\mathrm{PM}}$ of $12 \mathrm{~g} \mathrm{~kg}^{-1}$. Since an average $\kappa$ implies that all particles have the same hygroscopicity, its use also narrows the range of critical supersaturations (i.e., ssat95-ssat 5 ) by up to $80 \%$ for these scenarios. On the other hand, an average hygroscopicity is correct to within $10 \%$ for the case of small particles $\left(\mathrm{CMD}_{325}\right.$ of $70 \mathrm{~nm}$, top of Fig. 5) and $29 \%$ for a case with co-emitted SVOCs $\left(\mathrm{EF}_{\mathrm{SVOC}}\right.$ of $\left.5.62 \mathrm{~g} \mathrm{~kg}^{-1}\right)$. Hence, there is

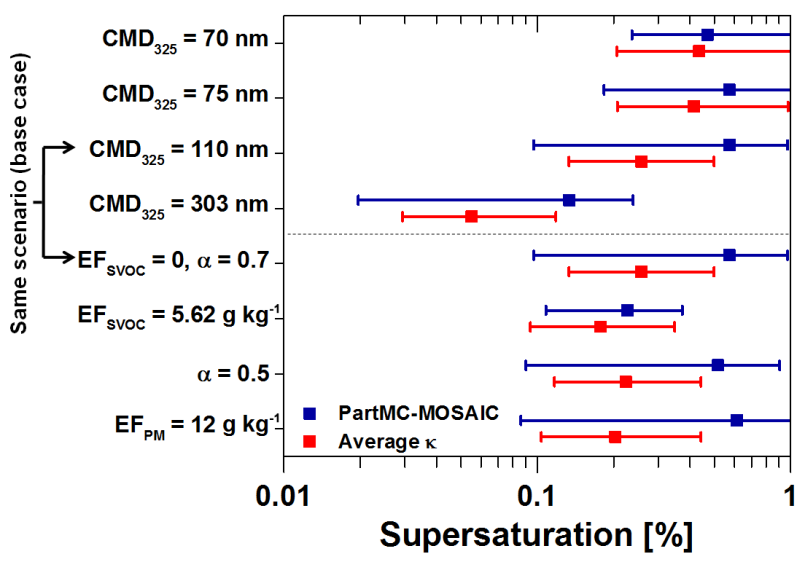

Figure 5. Critical supersaturation of particle populations (ssat 5 , ssat 50 , and ssat95), calculated with either the particle composition from PartMC-MOSAIC (blue), or an average $\kappa$ for all plume particles (red). The arrow highlights a "base case" simulation, i.e., an external mixture with EPPM of $4 \mathrm{~g} \mathrm{~kg}^{-1}, \mathrm{CMD}_{325}$ of $110 \mathrm{~nm}, \alpha=0.7$, and $\mathrm{EF}_{\mathrm{SVOC}}=0$. All other cases shown here are variations of this base case, obtained by changing one of the parameters as indicated in the labels. The horizontal dotted line separates scenarios testing the sensitivity to initial size (above), or SVOCs, dilution rate, or $\mathrm{EF}_{\mathrm{PM}}$ (below).

less need to understand the initial mixing state when plume particles have either a small size at emission or SVOCs are co-emitted. This is consistent with the findings of Fierce et al. (2013) in their study of CCN formation from diesel emissions under atmospheric aging, that is, that $\mathrm{CCN}$ number is less sensitive to initial mixing state under rapid aging by condensation.

\subsection{Role of Aitken-mode particles in determining plume-exit $\mathrm{CCN}$}

In Sect. 3.2 we showed that small particles, i.e., those with a $\mathrm{CMD}_{325}$ smaller than $100 \mathrm{~nm}$, can substantially contribute to plume-exit CCN (Fig. 2). In this section we examine the $\mathrm{CCN}$ activity of these small particles when they are emitted in a bimodal distribution. We differentiate between homogeneous distributions, in which all particles have the same composition, or heterogeneous distributions, in which the Aitken mode is composed of ammonium sulfate and the accumulation mode contains BC and POA. For most of the simulations, we exclude co-emitted SVOCs in order to focus only on how the differently sized particles interact. All simulations use EFPM of $4 \mathrm{~g} \mathrm{~kg}^{-1}$.

Figure 6 shows $\mathrm{EI}_{\mathrm{CCN}}$ for different initial relative concentrations of the Aitken $\left(N_{0, \text { Aitken }}\right)$ and accumulation mode $\left(N_{0, \mathrm{Acc}}\right)$. We use the ratio between the two $\left(R_{\text {Ait }}=N_{0, \text { Aitken }} / N_{0, \text { Acc }}\right)$ to indicate this. The figure also shows whether plume-exit $\mathrm{CCN}$ originate in the accumulation mode, the Aitken mode, or both (colored areas). When particles are heterogeneously mixed at emission, $\mathrm{EI}_{\mathrm{CCN}}$ 

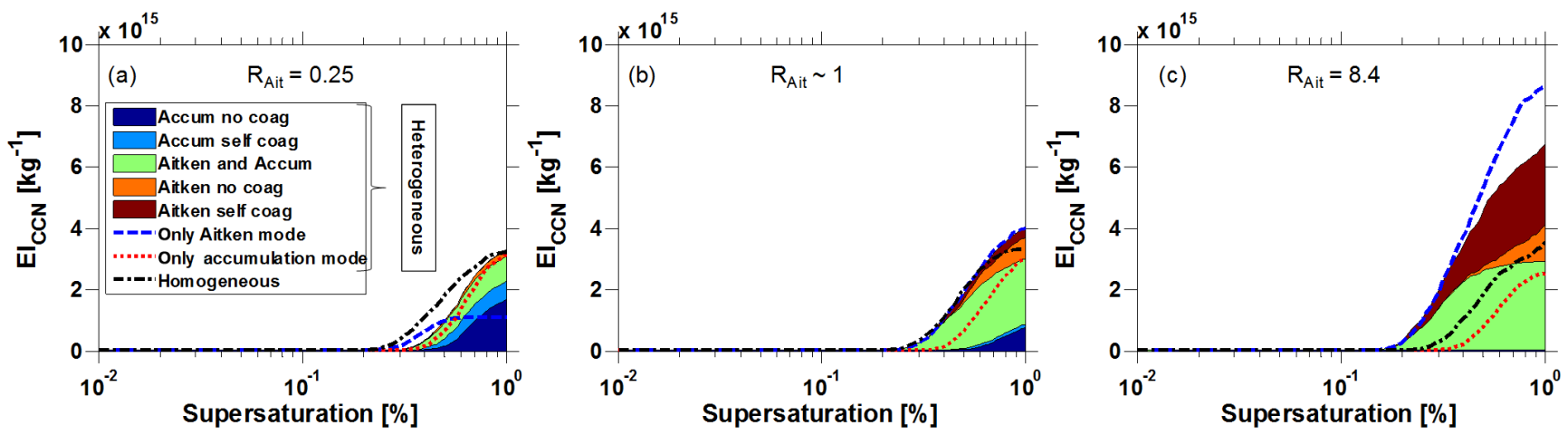

Figure 6. $\mathrm{EI}_{\mathrm{CCN}}$ for three different $R_{\text {Ait }}=N_{0 \text {, Ait }} / N_{0 \text {, Acc }}$ values. The scenario with $R_{\text {Ait }} \sim 1$ has $N_{0 \text {, Ait }}=1.6 \times 10^{14} \mathrm{~m}^{-3}$ and $N_{0, \text { Acc }}=1.2 \times 10^{14} \mathrm{~m}^{-3}$. The colored area corresponds to a heterogeneous bimodal distribution, each color describing the source of the particle that is $\mathrm{CCN}$-active at plume exit. The label "self coag" refers to particles that have coagulated only with particles from the same mode. "no coag" refers to particles that have not coagulated with any other particle type. The dashed blue and red lines correspond to a repetition of the simulation but with either the accumulation or Aitken mode removed, respectively. The black line corresponds to a homogeneous bimodal distribution, using the same $R_{\text {Ait }}$ values.
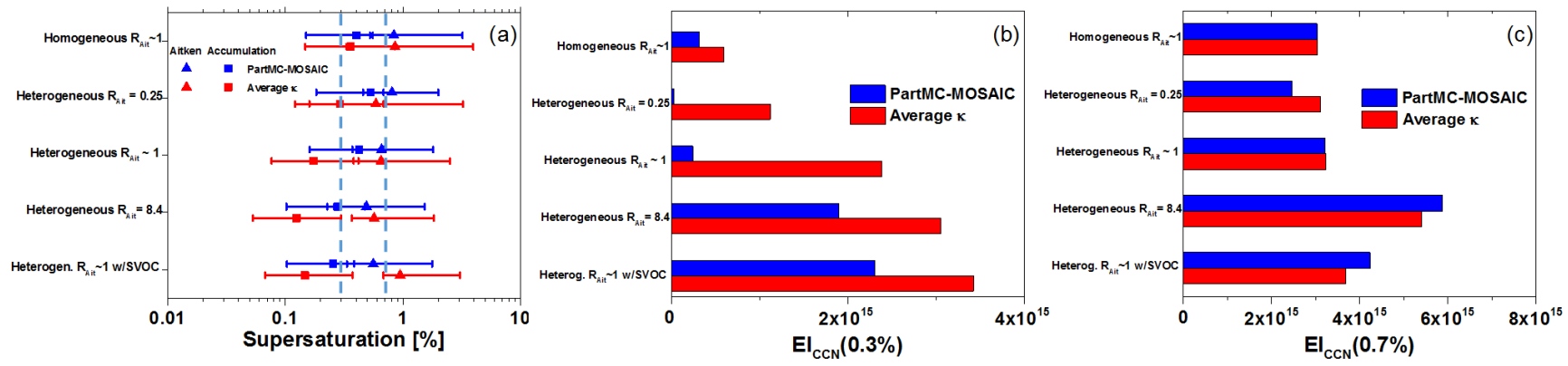

Figure 7. (a) ssat 5 , ssat 50 , and ssat 95 of homogeneous and heterogeneous bimodal distributions with different $R_{\text {Ait }}$ values, calculated separately for the Aitken mode (triangles) and accumulation mode (squares). Calculations were made with either the composition from PartMC-MOSAIC (blue), or using an average $\kappa$ for all particles (red). The vertical blue lines highlight $s_{\mathrm{sat}}$ of 0.3 and $0.7 \%$. (b) EI $\mathrm{CCN}$ for the same scenarios for $s_{\text {sat }}$ of $0.3 \%$, and (c) $s_{\text {sat }}$ of $0.7 \%$.

change by up to a factor of 2 from $R_{\text {Ait }}$ of 0.25 (Fig. 6a) to 8.4 (Fig. 6c).

Figure 6 also shows the CCN spectra if the same size distribution were emitted with a homogeneous composition (black dashed lines). When the homogeneous-composition curves differ from the heterogeneous scenario (area graph), then identifying compositional differences between Aitken and accumulation mode is important. Also shown in the Figure are the $\mathrm{CCN}$ if the accumulation-mode component of the size distribution were emitted alone (red dotted lines), and if the Aitken-mode component were emitted alone (blue dashed lines). Comparison between the bimodal result and the accumulation or Aitken-mode spectra shows how the interaction between the modes affects plume-exit $\mathrm{CCN}$. When these curves differ, plume-exit $\mathrm{CCN}$ would differ if the two modes were emitted simultaneously or sequentially.

For $R_{\text {Ait }}$ less than 1 (Fig. 6a), most of the $\mathrm{CCN}$ originate with accumulation-mode particles. $\mathrm{EI}_{\mathrm{CCN}}$ decreases by less than $17 \%$ when the simulation is repeated with the Aitken mode removed (red dashed line). On the other hand, when $N_{0, \text { Aitken }}$ is similar to $N_{0, \text { Acc }}$ (Fig. 6b), most of the CCN have a component from the Aitken mode. A simulation using only the Aitken mode gives $\mathrm{EI}_{\mathrm{CCN}}$ within a few percent of the bimodal distribution (blue dashed line), indicating that the accumulation mode does not contribute much to $\mathrm{EI}_{\mathrm{CCN}}$. When the Aitken-mode number concentration is much higher than that in the accumulation mode (Fig. 6c), most CCN also have a component from the Aitken mode, and the presence of the accumulation mode can actually decrease $\mathrm{EI}_{\mathrm{CCN}}$ due to the higher coagulation rate and particle loss, as shown by the comparison with the Aitken-only simulation (blue dashed

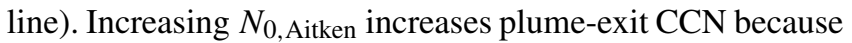
it increases the inorganic mass in the plume (by a factor of 4 in Fig. 6c compared to Fig. 6b), and also the hygroscopicity of POA and BC particles that coagulate with inorganic particles, as discussed in Sect. 3.4.

When particles are initialized with a homogeneous composition (black lines in Fig. 6), the number of particles origi- 
nally in the Aitken mode has a small effect on $\mathrm{EI}_{\mathrm{CCN}}$. Varying $R_{\text {Ait }}$ from the minimum (Fig. 6a) to the maximum case (Fig. 6c) changes $\mathrm{EI}_{\mathrm{CCN}}$ by $7 \%$, because the accumulation mode is already hygroscopic enough to become CCN.

Figure 7 summarizes plume-exit properties for simulations in which the initial distribution is a bimodal, heterogeneous distribution. Figure 7 a shows the critical supersaturation distribution within each particle population for the composition from PartMC-MOSAIC (blue), beginning with either a homogeneous or a heterogeneous population. The critical saturation that would be predicted with the use of an average $\kappa$ across all particles is also shown (red). Accumulation mode (squares) and Aitken mode (triangles) are separated. In the heterogeneous case, the inorganic mass is found in the Aitken mode; artificially spreading this mass across the entire particle distribution with an average $\kappa$ leads to overestimating the critical supersaturation of the Aitken mode and underestimating that of the accumulation mode.

Figure $7 \mathrm{~b}$ and $\mathrm{c}$ summarize $\mathrm{EI}_{\mathrm{CCN}}$ for two atmospherically relevant values of $s_{\mathrm{sat}}: 0.3$ and $0.7 \%$. At $s_{\mathrm{sat}}$ of $0.3 \%$ (Fig. 7b), the use of an average $\kappa$ disagrees with PartMC results by $61 \%$ for $R_{\text {Ait }}$ of 8.4 , to a factor of 47 for $R_{\text {Ait }}$ of 0.25 . This occurs because the uncoagulated particles emitted at $R_{\text {Ait }}$ of 0.25 have a great diversity in composition. When SVOCs are co-emitted, particles become hygroscopic and also reduce the diversity in $\kappa$; the estimated $\mathrm{EI}_{\mathrm{CCN}}$ agrees within $48 \%$ at $s_{\text {sat }}$ of $0.3 \%$. At higher supersaturations ( $s_{\text {sat }}$ of $0.7 \%$ in Fig. $7 \mathrm{c}$ ), most particles can function as $\mathrm{CCN}$, and the disagreement in $\mathrm{EI}_{\mathrm{CCN}}$ is at most $27 \%$.

\section{Summary and conclusion}

We modeled the evolution of a biofuel burning plume from emission until it reaches ambient temperature and $\mathrm{RH}$, for a variety of initial conditions and plume properties, with the objective of improving estimates of emitted $\mathrm{CCN}$ from residential biofuel combustion. The main findings of this study are as follows:

- After the plume dilutes and temperature drops below $350 \mathrm{~K}(t=2.4 \mathrm{~s}$ for $\alpha=\beta=0.7)$, particle size and $\kappa$ values change by less than $5 \%$ in all scenarios.

- Co-emission of SVOCs can be the main factor determining plume-exit CCN for hydrophobic or small particles, increasing $\mathrm{EI}_{\mathrm{CCN}}$ by up to 3 orders of magnitude. If particles are already large and hygroscopic enough to activate at emission, co-emission of SVOCs has a small effect on $\mathrm{EI}_{\mathrm{CCN}}$ (less than $5 \%$ ). When particles are emitted with smaller diameters, more $\mathrm{CCN}$ result from the same emitted mass, yet these particles activate at higher supersaturations. For particle diameters below $100 \mathrm{~nm}, 10-80 \%$ of the particles can serve as $\mathrm{CCN}$ at atmospheric supersaturations. This dependence on initial particle size and hygroscopicity is shown in Fig. 2.
- Some combinations of emission factor and size are impossible because of rapid plume coagulation. The upper limit of $\mathrm{EI}_{\mathrm{CCN}}$ is about $10^{16} \mathrm{~kg}^{-1}$. Depending on emission factor, particle size, and composition, some of these particles may not activate at low $s_{\text {sat }}$. For $\mathrm{EF}_{\mathrm{PM}}$ greater than $3 \mathrm{~g} \mathrm{~kg}^{-1}$, plume-exit CMD is at least $50 \mathrm{~nm}$.

- When particles are emitted as a bimodal distribution, the Aitken mode contributes less than $2 \%$ to the plume-exit $\mathrm{CCN}$ if both modes have the same composition.

- When the number concentration of more-hygroscopic Aitken-mode particles is high compared to lesshygroscopic accumulation-mode particles, the Aitkenmode particles can create additional $\mathrm{CCN}$ through selfcoagulation, but they have little effect on the $\mathrm{CCN}$ activity of accumulation-mode particles despite a large number of coagulation events between Aitken-mode and accumulation-mode particles.

- A simple model (monodisperse coagulation and average hygroscopicity) can be used to estimate plumeexit CCN within about $20 \%$ if particles are unimodal and have homogeneous composition. The simple model would underestimate particle loss by coagulation in a bimodal distribution by at least an order of magnitude.

- External mixtures become more internally mixed when particles are emitted in the Aitken mode, due to the higher coagulation rate, or with co-emitted SVOCs due to the homogenizing effect of the added mass.

- Plume-exit average hygroscopicity can be used to estimate $\mathrm{EI}_{\mathrm{CCN}}$ within 5-20\% if particles are emitted in the Aitken mode, even if externally mixed subpopulations exist within the Aitken mode. This is also true when SVOCs are co-emitted. The estimate improves as the particle size decreases, $\mathrm{EF}_{\mathrm{PM}}$ increases, or $\mathrm{EF}_{\mathrm{SVOC}}$ increases, since these factors enhance internal mixing in the particle population.

- On the other hand, if externally mixed particles are emitted in the accumulation mode without SVOCs, an average $\kappa$ overestimates hygroscopicity and hence overestimates $\mathrm{EI}_{\mathrm{CCN}}$ by up to a factor of 2 .

In summary, this work has systematically evaluated how and when plume processes alter particle populations, thus identifying two key cautions about using measured particle properties to represent CCN activity in atmospheric models. The first condition involves SVOCs, which homogenize particle populations and increase their CCN activity. This homogenization occurs only when SVOCs are truly co-emitted. Sequential emission, even if separated by a few seconds, results in greater heterogeneity; emissions from an entire burn cycle captured in an aging chamber may not represent plume-exit properties. The second caution occurs when there is a 
substantial Aitken mode. The Aitken members of a bimodal distribution likely never contribute to $\mathrm{CCN}$ activity, and when an Aitken-only mode is emitted, the plume-exit numbers are reduced by coagulation.

Atmospheric aging through coating or coagulation also affects the relationship between emitted particles and cloud properties (e.g., Fierce et al., 2015). The findings here are important because they describe (1) limitations in the emitted size distributions of primary particles, (2) the nature of directly emitted particles near sources, before atmospheric aging has occurred, and (3) the nature of atmospheric particles when other atmospheric aging is slow. The results given here characterize the nature of the particles at plume exit, after their evolution in a high-concentration environment where interactions with co-emissions prevail. The work of Fierce et al. (2016) describes subsequent evolution in the atmosphere, where factors external to the plume also play a role. Taken together, this body of work describes the complete evolution of biofuel burning emissions beginning at the source and continuing through the atmosphere.

Previous research has described how aerosol dynamics and atmospheric aging in young biomass burning plumes affect particle properties in the timescale of hours or days (e.g., Reid et al., 1999; Trentmann et al., 2002; Alvarado and Prinn, 2009). We have shown that for residential biofuel burning plumes the plumescale processes affect CCN activity within seconds after emission due to the high concentration of particles and gases, and the rapid dilution to ambient conditions. We also found that plume-exit $\mathrm{CCN}$ concentrations change by a few percent for the range of dilutions modeled here, whereas previous research on large, aged biomass burning plumes highlights the importance of dilution rate on plume chemistry and aerosol composition (Poppe et al., 1998; Shrivastava et al., 2006; Donahue et al., 2006). Furthermore, by using a particle-resolved model, we have quantified the homogenizing effect of condensation and coagulation in these small plumes.

Experimental verification of the important findings could include observations of $\mathrm{EI}_{\mathrm{CCN}}$ using a $\mathrm{CCN}$ counter, compared with gaseous carbon emissions, to demonstrate that $\mathrm{EI}_{\mathrm{CCN}}$ is limited to $10^{16} \mathrm{~kg}^{-1}$. The effect of co-emitted SVOCs could be evaluated by comparing $\mathrm{CCN}$ activity of a plume at different dilution ratios, where SVOCs would be expected to partition to the gas phase in the most dilute environments. The conditions under which the average-hygroscopicity assumption is expected to fail could be confirmed by performing CCN closure studies on aerosol generated with those specific characteristics; that is, aerosol size and composition could be measured with an Aerodyne mass spectrometer, and then $\mathrm{CCN}$ predicted from those values could be compared to measurements. Because biofuel emissions vary during the course of combustion, and because simultaneous emission affects the particle properties, these experiments should be conducted in real time or on emissions from isolated phases of burning.

Data availability. The input files and output of the PartMCMOSAIC simulations are available online at https://doi.org/10. 13012/B2IDB-6485436_V1.

\section{The Supplement related to this article is available online at https://doi.org/10.5194/acp-17-9399-2017-supplement.}

Competing interests. The authors declare that they have no conflict of interest.

Acknowledgements. Francisco Mena would like to thank the Fulbright Doctoral Program for their support in this research, Laura Fierce for her insightful comments, and Brent Biernbaum, Dylan Hayden, Eric McCoy, and Bill Riewerts for their experimental data of a plume temperature profile. This work was supported by the Department of Energy under grant DE-SC0006689.

Edited by: Markus Petters

Reviewed by: Jeffrey Reid and one anonymous referee

\section{References}

Akagi, S. K., Yokelson, R. J., Wiedinmyer, C., Alvarado, M. J., Reid, J. S., Karl, T., Crounse, J. D., and Wennberg, P. O.: Emission factors for open and domestic biomass burning for use in atmospheric models, Atmos. Chem. Phys., 11, 4039-4072, https://doi.org/10.5194/acp-11-4039-2011, 2011.

Alvarado, M. J. and Prinn, R. G.: Formation of ozone and growth of aerosols in young smoke plumes from biomass burning: 1. Lagrangian parcel studies, J. Geophys. Res.-Atmos., 114, D09306, https://doi.org/10.1029/2008jd011144, 2009.

Bauer, S. E., Menon, S., Koch, D., Bond, T. C., and Tsigaridis, K.: A global modeling study on carbonaceous aerosol microphysical characteristics and radiative effects, Atmos. Chem. Phys., 10, 7439-7456, https://doi.org/10.5194/acp-10-7439-2010, 2010.

Bond, T. C., Streets, D. G., Yarber, K. F., Nelson, S. M., Woo, J. H., and Klimont, Z.: A technology-based global inventory of black and organic carbon emissions from combustion, J. Geophys. Res.-Atmos., 109, D14203, https://doi.org/10.1029/2003jd003697, 2004.

Boundy, R. G., Diegel, S. W., Wright, L. L., and Davis, S. C.: Biomass Energy Data Book, 4th Edn., No. ORNL/TM-2011/446, Oak Ridge National Laboratory (ORNL), 2011.

Burling, I. R., Yokelson, R. J., Griffith, D. W. T., Johnson, T. J., Veres, P., Roberts, J. M., Warneke, C., Urbanski, S. P., Rear- 
don, J., Weise, D. R., Hao, W. M., and de Gouw, J.: Laboratory measurements of trace gas emissions from biomass burning of fuel types from the southeastern and southwestern United States, Atmospheric Chemistry and Physics, 10, 11115-11130, https://doi.org/10.5194/acp-10-11115-2010, 2010.

Che, H. C., Zhang, X. Y., Wang, Y. Q., Zhang, L., Shen, X. J., Zhang, Y. M., Ma, Q. L., Sun, J. Y., Zhang, Y. W., and Wang, T. T.: Characterization and parameterization of aerosol cloud condensation nuclei activation under different pollution conditions, Scientific Reports, 6, 24497, https://doi.org/10.1038/srep24497, 2016.

Ching, J., Riemer, N., and West, M.: Impacts of black carbon mixing state on black carbon nucleation scavenging: Insights from a particle-resolved model, J. Geophys. Res.-Atmos., 117, D23209, https://doi.org/10.1029/2012jd018269, 2012.

Christian, T. J., Yokelson, R. J., Cárdenas, B., Molina, L. T., Engling, G., and Hsu, S.-C.: Trace gas and particle emissions from domestic and industrial biofuel use and garbage burning in central Mexico, Atmos. Chem. Phys., 10, 565-584, https://doi.org/10.5194/acp-10-565-2010, 2010.

Chuen-Yu, C., Guenter, E., Xuefang, S., and Ting, Z.: Biofuel Combustion Emissions - Chemical and Physical Smoke Properties, Environmental Impact of Biofuels, 101-122, https://doi.org/10.5772/23430, 2011.

Dasch, J. M.: Particulate and gaseous emissions from wood-burning fireplaces, Environ. Sci. Technol., 16, 639-645, 1982.

Donahue, N. M., Robinson, A. L., Stanier, C. O., and Pandis, S. N.: Coupled partitioning, dilution, and chemical aging of semivolatile organics, Environ. Sci. Technol., 40, 2635-2643, https://doi.org/10.1021/es052297c, 2006.

Engelhart, G. J., Hennigan, C. J., Miracolo, M. A., Robinson, A. L., and Pandis, S. N.: Cloud condensation nuclei activity of fresh primary and aged biomass burning aerosol, Atmos. Chem. Phys., 12, 7285-7293, https://doi.org/10.5194/acp12-7285-2012, 2012.

Fierce, L., Riemer, N., and Bond, T. C.: When is cloud condensation nuclei activity sensitive to particle characteristics at emission?, J. Geophys. Res.-Atmos., 18, 13476-13488, https://doi.org/10.1002/2013JD020608, 2013.

Fierce, L., Riemer, N., and Bond, T. C.: Explaining variance in black carbon's aging timescale, Atmos. Chem. Phys., 15, 3173-3191, https://doi.org/10.5194/acp-15-3173-2015, 2015.

Fierce, L., Riemer, N., and Bond, T. C.: Toward Reduced Representation of Mixing State for Simulating Aerosol Effects on Climate, B. Am. Meteorol. Soc., 98, 971-980, https://doi.org/10.1175/BAMS-D-16-0028.1, 2016.

Gao, S., Hegg, D. A., Hobbs, P. V., Kirchstetter, T. W., Magi, B. I., and Sadilek, M.: Water-soluble organic components in aerosols associated with savanna fires in southern Africa: Identification, evolution, and distribution, J. Geophys. Res.-Atmos., 108, 8491, https://doi.org/10.1029/2002jd002324, 2003.

Hand, J. L., Day, D. E., McMeeking, G. M., Levin, E. J. T., Carrico, C. M., Kreidenweis, S. M., Malm, W. C., Laskin, A., and Desyaterik, Y.: Measured and modeled humidification factors of fresh smoke particles from biomass burning: role of inorganic constituents, Atmos. Chem. Phys., 10, 6179-6194, https://doi.org/10.5194/acp-10-6179-2010, 2010.

Hays, M. D., Geron, C. D., Linna, K. J., Smith, N. D., and Schauer, J. J.: Speciation of gas-phase and fine particle emissions from burning of foliar fuels, Environ. Sci. Technol., 36, 2281-2295, 2002.

Hedberg, E., Kristensson, A., Ohlsson, M., Johansson, C., Johansson, P. A., Swietlicki, E., Vesely, V., Wideqvist, U., and Westerholm, R.: Chemical and physical characterization of emissions from birch wood combustion in a wood stove, Atmos. Environ., 36, 4823-4837, 2002.

Hobbs, P. V. and Radke, L. F.: Cloud Condensation Nuclei from a Simulated Forest Fire, Science, 163, 279-280, https://doi.org/10.1126/science.163.3864.279, 1969.

Hobbs, P. V., Sinha, P., Yokelson, R. J., Christian, T. J., Blake, D. R., Gao, S., Kirchstetter, T. W., Novakov, T., and Pilewskie, P.: Evolution of gases and particles from a savanna fire in South Africa, J. Geophys. Res.-Atmos., 108, 8485, https://doi.org/10.1029/2002jd002352, 2003.

Holle, R. L.: Effects of Cloud Condensation Nuclei Due to Fires and Surface Sources During South Florida Droughts, J. Appl. Meteorol., 10, 62-69, https://doi.org/10.1175/15200450(1971)010<0062:EOCCND>2.0.CO;2, 1971.

Jacobson, M. Z.: Development and application of a new air pollution modeling system .2. Aerosol module structure and design, Atmos. Environ., 31, 131-144, https://doi.org/10.1016/13522310(96)00202-6, 1997.

Jacobson, M. Z.: A physically-based treatment of elemental carbon optics: Implications for global direct forcing of aerosols, Geophys. Res. Lett., 27, 217-220, 2000.

Jacobson, M. Z.: Short-term effects of controlling fossil-fuel soot, biofuel soot and gases, and methane on climate, Arctic ice, and air pollution health, J. Geophys. Res.-Atmos., 115, D14209, https://doi.org/10.1029/2009jd013795, 2010.

Jones, A.: Investigating the impacts of entrainment on nucleation scavenging of black carbon particles through particle-resolved simulations, MS, Atmospheric Sciences, University of Illinois at Urbana Champaign, http://hdl.handle.net/2142/49492 (last access: 13 July 2017), 2014.

Jost, C., Trentmann, J., Sprung, D., Andreae, M. O., McQuaid, J. B., and Barjat, H.: Trace gas chemistry in a young biomass burning plume over Namibia: Observations and model simulations, J. Geophys. Res.-Atmos., 108, 8482, https://doi.org/10.1029/2002jd002431, 2003.

Knudsen, J. N., Jensen, P. A., and Dam-Johansen, K.: Transformation and release to the gas phase of $\mathrm{Cl}, \mathrm{K}$, and $\mathrm{S}$ during combustion of annual biomass, Energ. Fuel., 18, 1385-1399, https://doi.org/10.1021/ef049944q, 2004.

Koch, D., Balkanski, Y., Bauer, S. E., Easter, R. C., Ferrachat, S., Ghan, S. J., Hoose, C., Iversen, T., Kirkevåg, A., Kristjansson, J. E., Liu, X., Lohmann, U., Menon, S., Quaas, J., Schulz, M., Seland, Ø., Takemura, T., and Yan, N.: Soot microphysical effects on liquid clouds, a multi-model investigation, Atmos. Chem. Phys., 11, 1051-1064, https://doi.org/10.5194/acp11-1051-2011, 2011.

Kodros, J. K., Scott, C. E., Farina, S. C., Lee, Y. H., L'Orange, C., Volckens, J., and Pierce, J. R.: Uncertainties in global aerosols and climate effects due to biofuel emissions, Atmos. Chem. Phys., 15, 8577-8596, https://doi.org/10.5194/acp-158577-2015, 2015.

Lewis, K. A., Arnott, W. P., Moosmüller, H., Chakrabarty, R. K., Carrico, C. M., Kreidenweis, S. M., Day, D. E., Malm, W. C., Laskin, A., Jimenez, J. L., Ulbrich, I. M., Huffman, J. A., 
Onasch, T. B., Trimborn, A., Liu, L., and Mishchenko, M. I.: Reduction in biomass burning aerosol light absorption upon humidification: roles of inorganically-induced hygroscopicity, particle collapse, and photoacoustic heat and mass transfer, Atmos. Chem. Phys., 9, 8949-8966, https://doi.org/10.5194/acp-9-89492009, 2009.

Li, X., Duan, L., Wang, S., Duan, J., Guo, X., Yi, H., Hu, J., Li, C., and Hao, J.: Emission characteristics of particulate matter from rural household biofuel combustion in China, Energ. Fuel., 21, 845-851, 2007.

Liousse, C., Devaux, C., Dulac, F., and Cachier, H.: Aging of savanna biomass burning aerosols: Consequences on their optical properties, J. Atmos. Chem., 22, 1-17, https://doi.org/10.1007/BF00708178, 1995.

Ludwig, J., Marufu, L. T., Huber, B., Andreae, M. O., and Helas, G.: Domestic combustion of biomass fuels in developing countries: A major source of atmospheric pollutants, J. Atmos. Chem., 44, 23-37, https://doi.org/10.1023/a:1022159910667, 2003.

Mann, G. W., Carslaw, K. S., Reddington, C. L., Pringle, K. J., Schulz, M., Asmi, A., Spracklen, D. V., Ridley, D. A., Woodhouse, M. T., Lee, L. A., Zhang, K., Ghan, S. J., Easter, R. C., Liu, X., Stier, P., Lee, Y. H., Adams, P. J., Tost, H., Lelieveld, J., Bauer, S. E., Tsigaridis, K., van Noije, T. P. C., Strunk, A., Vignati, E., Bellouin, N., Dalvi, M., Johnson, C. E., Bergman, T., Kokkola, H., von Salzen, K., Yu, F., Luo, G., Petzold, A., Heintzenberg, J., Clarke, A., Ogren, J. A., Gras, J., Baltensperger, U., Kaminski, U., Jennings, S. G., O'Dowd, C. D., Harrison, R. M., Beddows, D. C. S., Kulmala, M., Viisanen, Y., Ulevicius, V., Mihalopoulos, N., Zdimal, V., Fiebig, M., Hansson, H.-C., Swietlicki, E., and Henzing, J. S.: Intercomparison and evaluation of global aerosol microphysical properties among AeroCom models of a range of complexity, Atmos. Chem. Phys., 14, 4679-4713, https://doi.org/10.5194/acp-14-4679-2014, 2014.

Martin, M., Tritscher, T., Juranyi, Z., Heringa, M. F., Sierau, B., Weingartner, E., Chirico, R., Gysel, M., Prevot, A. S. H., Baltensperger, U., and Lohmann, U.: Hygroscopic properties of fresh and aged wood burning particles, J. Aerosol Sci., 56, 1529, https://doi.org/10.1016/j.jaerosci.2012.08.006, 2013.

Mason, S. A., Field, R. J., Yokelson, R. J., Kochivar, M. A., Tinsley, M. R., Ward, D. E., and Hao, W. M.: Complex effects arising in smoke plume simulations due to inclusion of direct emissions of oxygenated organic species from biomass combustion, J. Geophys. Res.-Atmos., 106, 1252712539, https://doi.org/10.1029/2001jd900003, 2001.

McGraw, R.: Description of aerosol dynamics by the quadrature method of moments, Aerosol Sci. Tech., 27, 255-265, https://doi.org/10.1080/02786829708965471, 1997.

Nussbaumer, T.: Combustion and co-combustion of biomass: fundamentals, technologies, and primary measures for emission reduction, Energ. Fuel., 17, 1510-1521, https://doi.org/10.1021/ef030031q, 2003.

Parmar, R. S., Welling, M., Andreae, M. O., and Helas, G.: Water vapor release from biomass combustion, Atmos. Chem. Phys., 8 , 6147-6153, https://doi.org/10.5194/acp-8-6147-2008, 2008.

Petters, M. D. and Kreidenweis, S. M.: A single parameter representation of hygroscopic growth and cloud condensation nucleus activity, Atmos. Chem. Phys., 7, 1961-1971, https://doi.org/10.5194/acp-7-1961-2007, 2007.
Poppe, D., Koppmann, R., and Rudolph, J.: Ozone formation in biomass burning plumes: Influence of atmospheric dilution, Geophys. Res. Lett., 25, 3823-3826, https://doi.org/10.1029/1998g1900046, 1998.

Reid, J. S. and Hobbs, P. V.: Physical and optical properties of young smoke from individual biomass fires in Brazil, J. Geophys. Res.Atmos., 103, 32013-32030, https://doi.org/10.1029/98jd00159, 1998.

Reid, J. S., Hobbs, P. V., Ferek, R. J., Blake, D. R., Martins, J. V., Dunlap, M. R., and Liousse, C.: Physical, chemical, and optical properties of regional hazes dominated by smoke in Brazil, J. Geophys. Res.-Atmos., 103, 32059-32080, https://doi.org/10.1029/98jd00458, 1998.

Reid, J. S., Eck, T. F., Christopher, S. A., Hobbs, P. V., and Holben, B.: Use of the Angstrom exponent to estimate the variability of optical and physical properties of aging smoke particles in Brazil, J. Geophys. Res.-Atmos., 104, 27473-27489, https://doi.org/10.1029/1999jd900833, 1999.

Riemer, N., West, M., Zaveri, R. A., and Easter, R. C.: Simulating the evolution of soot mixing state with a particleresolved aerosol model, J. Geophys. Res.-Atmos., 114, D09202, https://doi.org/10.1029/2008jd011073, 2009.

Riemer, N., West, M., Zaveri, R., and Easter, R.: Estimating black carbon aging time-scales with a particleresolved aerosol model, J. Aerosol Sci., 41, 143-158, https://doi.org/10.1016/j.jaerosci.2009.08.009, 2010.

Roden, C. A., Bond, T. C., Conway, S., Benjamin, A., and Pinel, O.: Emission factors and real-time optical properties of particles emitted from traditional wood burning cookstoves, Environ. Sci. Technol., 40, 6750-6757, https://doi.org/10.1021/es052080i, 2006.

Schell, B., Ackermann, I. J., Hass, H., Binkowski, F. S., and Ebel, A.: Modeling the formation of secondary organic aerosol within a comprehensive air quality model system, J. Geophys. Res.-Atmos., 106, 28275-28293, https://doi.org/10.1029/2001jd000384, 2001.

Seinfeld, J. H. and Pandis, S. N.: Atmospheric chemistry and physics: from air pollution to climate change, Atmospheric chemistry and physics: from air pollution to climate change, xxviii, 203 pp., 2006.

Seinfeld, J. H., Bretherton, C., Carslaw, K. S., Coe, H., DeMott, P. J., Dunlea, E. J., Feingold, G., Ghan, S., Guenther, A. B., Kahn, R., Kraucunas, I., Kreidenweis, S. M., Molina, M. J., Nenes, A., Penner, J. E., Prather, K. A., Ramanathan, V., Ramaswamy, V., Rasch, P. J., Ravishankara, A. R., Rosenfeld, D., Stephens, G., and Wood, R.: Improving our fundamental understanding of the role of aerosol-cloud interactions in the climate system, P. Natl. Acad. Sci. USA, 113, 5781-5790, 2016.

Shrivastava, M. K., Lipsky, E. M., Stanier, C. O., and Robinson, A. L.: Modeling semivolatile organic aerosol mass emissions from combustion systems, Environ. Sci. Technol., 40, 26712677, https://doi.org/10.1021/es0522231, 2006.

Tian, J., Riemer, N., West, M., Pfaffenberger, L., Schlager, H., and Petzold, A.: Modeling the evolution of aerosol particles in a ship plume using PartMC-MOSAIC, Atmos. Chem. Phys., 14, 53275347, https://doi.org/10.5194/acp-14-5327-2014, 2014.

Tissari, J., Hytönen, K., Lyyränen, J., and Jokiniemi, J.: A novel field measurement method for determining fine particle and gas 
emissions from residential wood combustion, Atmos. Environ., 41, 8330-8344, 2007.

Torvela, T., Tissari, J., Sippula, O., Kaivosoja, T., Leskinen, J., Virén, A., Lähde, A., and Jokiniemi, J.: Effect of wood combustion conditions on the morphology of freshly emitted fine particles, Atmos. Environ., 87, 65-76, https://doi.org/10.1016/j.atmosenv.2014.01.028, 2014.

Trentmann, J., Andreae, M. O., Graf, H. F., Hobbs, P. V., Ottmar, R. D., and Trautmann, T.: Simulation of a biomassburning plume: Comparison of model results with observations, J. Geophys. Res.-Atmos., 107, AAC 5-1-AAC 5-15, https://doi.org/10.1029/2001jd000410, 2002.

Trentmann, J., Yokelson, R. J., Hobbs, P. V., Winterrath, T., Christian, T. J., Andreae, M. O., and Mason, S. A.: An analysis of the chemical processes in the smoke plume from a savanna fire, J. Geophys. Res.-Atmos., 110, D12301, https://doi.org/10.1029/2004jd005628, 2005.

Trentmann, J., Luderer, G., Winterrath, T., Fromm, M. D., Servranckx, R., Textor, C., Herzog, M., Graf, H.-F., and Andreae, M. O.: Modeling of biomass smoke injection into the lower stratosphere by a large forest fire (Part I): reference simulation, Atmos. Chem. Phys., 6, 5247-5260, https://doi.org/10.5194/acp6-5247-2006, 2006.

Twomey, S.: Pollution and the planetary albedo, Atmos. Environ., 8, 1251-1256, https://doi.org/10.1016/0004-6981(74)90004-3, 1974.

Vakkari, V., Kerminen, V.-M., Beukes, J. P., Tiitta, P., van Zyl, P. G., Josipovic, M., Venter, A. D., Jaars, K., Worsnop, D. R., Kulmala, M., and Laakso, L.: Rapid changes in biomass burning aerosols by atmospheric oxidation, Geophys. Res. Lett., 41, 2644-2651, https://doi.org/10.1002/2014g1059396, 2014.

von Glasow, R., Lawrence, M. G., Sander, R., and Crutzen, P. J.: Modeling the chemical effects of ship exhaust in the cloudfree marine boundary layer, Atmos. Chem. Phys., 3, 233-250, https://doi.org/10.5194/acp-3-233-2003, 2003.
Wang, J., Cubison, M. J., Aiken, A. C., Jimenez, J. L., and Collins, D. R.: The importance of aerosol mixing state and size-resolved composition on $\mathrm{CCN}$ concentration and the variation of the importance with atmospheric aging of aerosols, Atmos. Chem. Phys., 10, 7267-7283, https://doi.org/10.5194/acp10-7267-2010, 2010.

Warner, J. and Twomey, S.: The Production of Cloud Nuclei by Cane Fires and the Effect on Cloud Droplet Concentration, J. Atmos. Sci., 24, 704-706, https://doi.org/10.1175/15200469(1967)024<0704:TPOCNB>2.0.CO;2, 1967.

Whitby, E. R. and McMurry, P. H.: Modal aerosol dynamics modeling, Aerosol Sci. Tech., 27, 673-688, https://doi.org/10.1080/02786829708965504, 1997.

Williams, A., Jones, J. M., Ma, L., and Pourkashanian, M.: Pollutants from the combustion of solid biomass fuels, Prog. Energ. Combust., 38, 113-137, https://doi.org/10.1016/j.pecs.2011.10.001, 2012.

Woo, J. H., Streets, D. G., Carmichael, G. R., Tang, Y. H., Yoo, B., Lee, W. C., Thongboonchoo, N., Pinnock, S., Kurata, G., Uno, I., Fu, Q. Y., Vay, S., Sachse, G. W., Blake, D. R., Fried, A., and Thornton, D. C.: Contribution of biomass and biofuel emissions to trace gas distributions in Asia during the TRACE-P experiment, J. Geophys. Res.-Atmos., 108, 8812, https://doi.org/10.1029/2002JD003200, 2003.

Zaveri, R. A., Easter, R. C., Fast, J. D., and Peters, L. K.: Model for Simulating Aerosol Interactions and Chemistry (MOSAIC), J. Geophys. Res.-Atmos., 113, D13204, https://doi.org/10.1029/2007jd008782, 2008.

Zaveri, R. A., Barnard, J. C., Easter, R. C., Riemer, N., and West, M.: Particle-resolved simulation of aerosol size, composition, mixing state, and the associated optical and cloud condensation nuclei activation properties in an evolving urban plume, J. Geophys. Res.-Atmos., 115, D17210, https://doi.org/10.1029/2009jd013616, 2010. 